\title{
Nanocrystal Quantum Dot Devices: How the Lead Sulfide (PbS) System Teaches Us the Importance of Surfaces
}

\author{
Weyde M. M. Lin ${ }^{a}$, Maksym Yarema*a, Mengxia Liu ${ }^{b}$, Edward Sargent ${ }^{b}$, and Vanessa Wood ${ }^{* a}$
}

\begin{abstract}
Semiconducting thin films made from nanocrystals hold potential as composite hybrid materials with new functionalities. With nanocrystal syntheses, composition can be controlled at the sub-nanometer level, and, by tuning size, shape, and surface termination of the nanocrystals as well as their packing, it is possible to select the electronic, phononic, and photonic properties of the resulting thin films. While the ability to tune the properties of a semiconductor from the atomistic- to macro-scale using solution-based techniques presents unique opportunities, it also introduces challenges for process control and reproducibility. In this review, we use the example of well-studied lead sulfide (PbS) nanocrystals and describe the key advances in nanocrystal synthesis and thin-film fabrication that have enabled improvement in performance of photovoltaic devices. While research moves forward with novel nanocrystal materials, it is important to consider what decades of work on $\mathrm{PbS}$ nanocrystals has taught us and how we can apply these learnings to realize the full potential of nanocrystal solids as highly flexible materials systems for functional semiconductor thin-film devices. One key lesson is the importance of controlling and manipulating surfaces.
\end{abstract}

Keywords: Lead sulfide colloidal nanocrystals $\cdot$ Nanocrystal quantum dot devices $\cdot$ Semiconductor nanocrystals

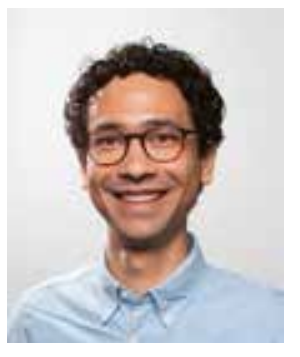

Weyde M. M. Lin is a recent $\mathrm{PhD}$ graduate from the Materials and Device Engineering Group, Institute for Electronics, Department of Information Technology and Electrical Engineering, ETH Zurich. His thesis, supervised by Prof. Vanessa Wood, is devoted to colloidal quantum dots and their thin film devices, particularly to lead chalcogenide materials. Previously, he studied materials science in ETHZurich and took international research visits to University of Pennsylvania (Christopher Murray Lab) and University of Toronto (Ted Sargent Lab).

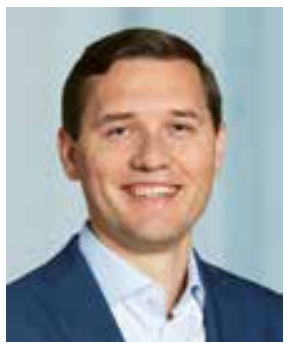

Maksym Yarema is an Assistant Professor at the Institute for Electronics in the Department of Information Technology and Electrical Engineering at ETH Zurich. He leads the Chemistry and Materials Design Group, exploring novel compositions of colloidal nanomaterials and their applications for phase-change memory, optoelectronic, and energy storage technologies. He earned BSc and MSc degrees in chemistry from Lviv National University and a $\mathrm{PhD}$ in nanoscience and nanotechnology from the Johannes Kepler University Linz. He was awarded several research grants, including Marie Curie Postdoctoral fellowship, SNSF Ambizione fellowship, and ERC Starting grant.

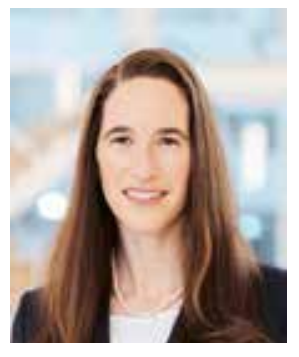

Vanessa Wood is a Full Professor and Chair at the Institute for Electronics in the Department of Information Technology and Electrical Engineering at ETH Zurich. She is a director of the Materials and Device Engineering Group, seeking a deeper understanding of various energy applications through the accurate engineering and characterization of nanomaterials. She holds a Bachelors in Science from Yale University, a Masters in Electrical Engineering and Computer Science from MIT, and a $\mathrm{PhD}$ in Electrical Engineering from MIT. She is a recipient of many awards, among which the 2014 Science Prize in Electrochemistry, ERC Starting grant, ETH Golden Owl teaching award, and MRS 2018 Outstanding Young Investigator Award.

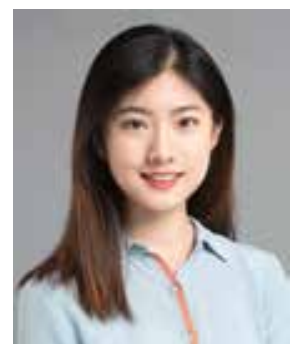

Mengxia Liu is a post-doctoral fellow in the Cavendish Laboratory at the University of Cambridge. She received her BSc degree in Materials Science and Engineering from the Tianjin University in 2014, and her $\mathrm{PhD}$ degree in Electrical and Computer Engineering from the University of Toronto in 2018. Mengxia was selected as an MIT EECS Rising Star in 2018. She is a recipient of 2019 Marie Skłodowska-Curie Actions Seal of Excellence Award and 2018 Chinese Government Award for Outstanding Self-Financed Students Abroad. She is currently a Review Editor for the Frontiers in Energy Research. 


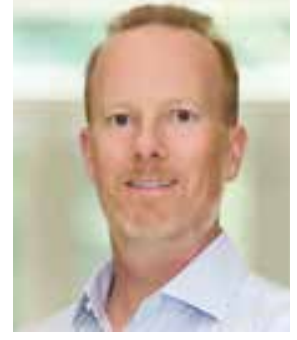

Ted Sargent holds the rank of University Professor in the Edward S. Rogers Sr. Department of Electrical and Computer Engineering at the University of Toronto. He also serves as Vice President-Research for the University. He received his BSc. Eng. (Engineering Physics) from Queen's University in 1995 and his $\mathrm{PhD}$ in Electrical and Computer Engineering (Photonics) from the University of Toronto in 1998. His publications have been cited 60,000 times.

\section{Introduction}

Colloidally synthesized semiconductor nanocrystals have become a distinct class of materials, functional in a multitude of optoelectronic applications. ${ }^{[1]}$ Wet chemistry synthesis is fast and customizable, which allows for control over morphology and surface properties of nanocrystals (i.e. size, shape, surface ligands, etc.). Furthermore, colloidal synthesis can be adapted to nearly any materials system. ${ }^{[2,3]}$ Nanocrystal thin films can be fabricated directly from the liquid phase, thus avoiding the use of expensive vacuum deposition techniques. In combination with other materials properties, such as high absorptivity, this results in significantly lower fabrication cost of devices. However, compared to traditional solid-state semiconductors, there are many choices during the synthesis (e.g. precursors), thin-film deposition (e.g. fabrication methods), and post-deposition treatments (e.g. ligand-exchange methods), which greatly influence the final thin-film properties. All these individual steps need to be carefully tuned for the optimal thin-film quality. It is therefore crucial to have reliable characterization methods at each step of the process.

In this review, we focus on lead sulfide $(\mathrm{PbS})$ colloidal nanocrystals since it is one of the most-studied semiconductor nanomaterials. ${ }^{[4]}$ Due to quantum confinement, the energy band gap of $\mathrm{PbS}$ can be increased from the $0.42 \mathrm{eV}^{[5]}$ in bulk to $1.8 \mathrm{eV}$ with $1.2 \mathrm{~nm}$ radius nanocrystals. ${ }^{[6]}$ Solar cells, photodetectors, and hybrid infrared cameras benefit from solution-phase processability, high absorption coefficients, and relatively good air stability of $\mathrm{PbS}$ nanocrystals. ${ }^{[7-9]}$ As a result, $\mathrm{PbS}$ nanocrystals have become a model system for which a large number of fundamental, computational and experimental investigations have been performed. ${ }^{[10-12]}$ The vast amount of research carried out on $\mathrm{PbS}$ make it an ideal system from which to gain valuable insight into colloidal synthesis, post-synthesis treatment, and thin film fabrication. This knowledge can be applied to the development of other nanocrystals material systems for optoelectronic devices.

We structure the review in four sections detailing the fabrication and characterization steps of $\mathrm{PbS}$ nanocrystals and thin films (Fig. 1). In the first section, we focus on approaches to control size, shape, composition, and surface of the individual nanocrystal and discuss synthesis protocols that enable such a control. The second section is dedicated to the characterization of the nanocrystals, in which we list the primary methods used to determine the shape of the nanocrystals, their size and size distribution as well as chemical composition and optical properties. In the third section, we describe the methods for packing of individual nanocrystals into nanocrystals thin film and compare their advantages and disadvantage in terms of film quality and material efficiency. In the fourth section, we

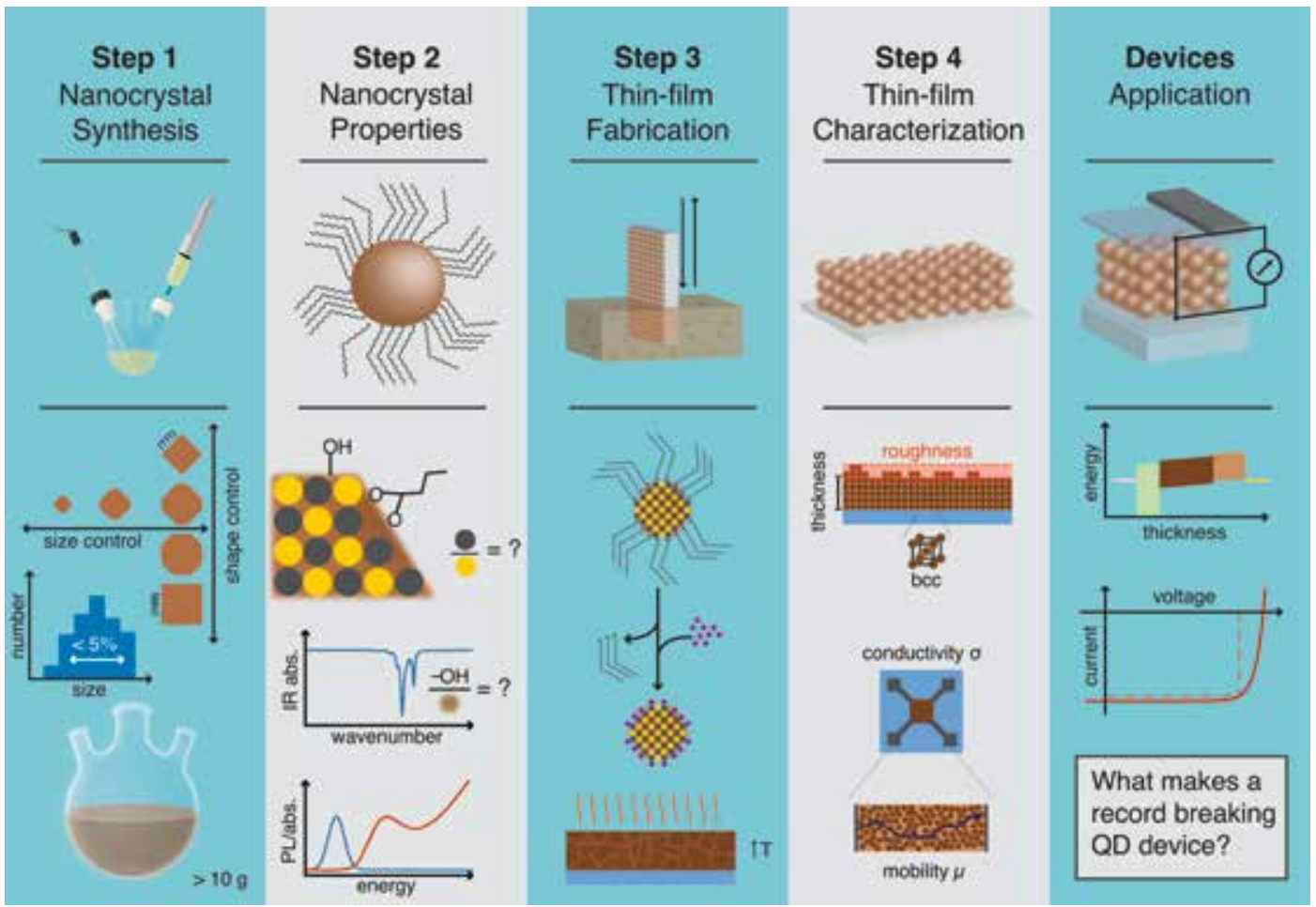

Fig. 1. From raw materials to functioning nanocrystal-based device in four steps. From left to right: (Step 1: Nanocrystal synthesis) By varying the synthesis parameters, precise control of shape and size as well as good size distribution can be achieved. Syntheses can be scaled up to obtain more than $10 \mathrm{~g}$ of product from a single batch. (Step 2: Nanocrystal properties) Characterization of the composition and optical properties of the synthesized nanocrystals through a combination of techniques like determining the atomic ratio with inductively coupled plasma atomic emission spectroscopy (ICP-AES), the organic surface-ligand coverage with Fourier transform infrared spectroscopy (FTIR), and the photoluminescence and absorption spectroscopy is key. (Step 3: Thin-film fabrication) The choice of fabrication methods and optional post-deposition treatments can be selected to tune the NC surface and the packing of the NCs. (Step 4: Thin-film characterization) The structural and electrical properties of fabricated thin films should be characterized. (Devices: Application) To design a nanocrystal-based device requires careful consideration of the film properties such as conduction and valance band levels, band gap, electronic transport etc. The device performance is a combination of the properties of the nanocrystal thin film as well as the engineering of the device. 
comment on the characterization of nanocrystal thin films. In the last section, we use nanocrystal-based solar cells as an example device and trace some of the key innovations in the last years that have led to improved performance. The work on $\mathrm{PbS}$ nanocrystals indicates that as new types of material systems are developed and integrated into devices, it is of strategic importance to understand each processing step - in particular the methods to control the nanocrystal surface during synthesis and thin film fabrication as well as the strategies to lever the control of the nanocrystal surface for device applications.

\section{Step 1: Synthesis of PbS Nanocrystals}

Excellent size control (1 to $50 \mathrm{~nm}$ ) and narrow size distributions are attained for $\mathrm{PbS}$ nanocrystals. ${ }^{[13-17]} \mathrm{PbS}$ nanocrystals can be prepared in a diversity of shapes, including spheres (dots), cubes, stars, rods, plates, and sheets. Table 1 and Fig. 2 summarize synthetic efforts towards high-quality $\mathrm{PbS}$ nanocrystals.

Monodisperse $\mathrm{PbS}$ nanocrystals are often synthesized using a hot-injection approach. Typically, sulfur precursor is swiftly added to the hot reaction mixture, which contains $\mathrm{Pb}$ halide or oleate. Most synthetic recipes are built upon two original hotinjection protocols: oleate-based and oleylamine-based syntheses of PbS nanocrystals. ${ }^{[18,19]}$ Non-injection heating-up methods offer scalability and expand the shape control to platelets, sheets, and branched morphologies. ${ }^{[20-22]}$

\section{Oleate-based Synthesis}

In 2003, Hines and Scholes reported the first synthesis of monodisperse $\mathrm{PbS}$ nanocrystals with tunable size, ${ }^{[18]}$ which has emerged as a highly practical approach since it is a fast, single-flask synthesis using commercially available reagents. This recipe is based on fast addition of highly-reactive organometallic sulfur precursor, bis(trimethylsilyl)sulfide, to the reaction solution, containing $\mathrm{Pb}(\mathrm{II})$ oleate in weakly-coordinating solvent, 1-octadecene. The Pb-oleate precursor is prepared in situ from $\mathrm{PbO}$ and oleic acid, prior to the S-precursor injection. The size control can be attained by two means: (i) adding excessive oleic acid (leading to larger nanocrystal sizes), and (ii) tuning the temperature profile after injection at 150 ${ }^{\circ} \mathrm{C}$, either by maintaining the reaction flask at constant temperature between $80-140^{\circ} \mathrm{C}$ or by slow natural cooling to room temperature. Most importantly, the obtained $\mathrm{PbS}$ nanocrystals exhibit narrow size distributions without the time-consuming size-selective precipitation process, which was the tedious extra step used to obtain state-of-the-art at that time.[18]

The chemistry of the oleate-based synthesis has likely made it particularly beneficial for use in optoelectronics, where it is noteworthy that all NREL record PbS nanocrystal solar cells were fabricated from $\mathrm{PbS}$ nanocrystals prepared via the oleatebased approach. ${ }^{[2]}$ One possible explanation for this may stem from the structure of bis(trimethylsilyl)sulfide. The trimethylsilyl (TMS) functional group is known as a 'good leaving group' in organic chemistry, meaning that for the bis(trimethylsilyl)sulfide precursor the trimethylsilyl easily leaves behind highly-reactive $S$ centers with the oxidation number -2 . This leads to fast reaction with $\mathrm{Pb}(+2)$ precursor, reducing the likelihood of possible redox processes and concurrent reactions. The use of excessive $\mathrm{Pb}$ precursor (the synthesis uses 2:1 molar ratio of $[\mathrm{Pb}]:[\mathrm{S}])^{[18]}$ is beneficial for optoelectronics, as this leads to Pb-rich surface of $\mathrm{PbS}$ nanocrystals, which is known to be more resistant towards surface oxidation or etching. ${ }^{[25]}$

\section{Modifications of Oleate-based Synthesis}

There are a large number of reported modifications to the original oleate-based synthesis of PbS nanocrystals, in which parameters are tuned to improve control over size, composition, and chemical yield of the synthesis.

Table 1. Selected syntheses of monodisperse PbS nanocrystals (sorted by publication year)

\begin{tabular}{|c|c|c|c|c|c|c|}
\hline $\begin{array}{l}\mathrm{Pb} \\
\text { precursor }\end{array}$ & $\begin{array}{l}\text { S } \\
\text { precursor }\end{array}$ & $\begin{array}{l}\text { Solvent(s) \& } \\
\operatorname{ligand}(\mathbf{s})\end{array}$ & Method & $\begin{array}{l}\text { Time \& } \\
\text { temperature }\end{array}$ & $\begin{array}{l}\text { Size \& } \\
\text { shape }\end{array}$ & Ref. \\
\hline $\mathrm{PbO}$ & $\mathrm{S}\left(\mathrm{SiMe}_{3}\right)_{2}$ & OA, ODE & $\mathrm{HI}$ & $\begin{array}{l}\text { injection at } 150{ }^{\circ} \mathrm{C} \text {, growth } \\
5 \text { min at } 80-140{ }^{\circ} \mathrm{C}\end{array}$ & dots, $2-8 \mathrm{~nm}$ & [18] \\
\hline $\mathrm{PbCl}_{2}$ & $\mathrm{~S}$ in OLA & OLA & $\mathrm{HI}$ & $\begin{array}{l}\text { injection at } 120^{\circ} \mathrm{C} \text {, growth } \\
0.25-500 \mathrm{~min} \text { at } 100^{\circ} \mathrm{C}\end{array}$ & dots, $4-6 \mathrm{~nm}$ & [19] \\
\hline $\mathrm{Pb}$ acetate & Thioacetamide & $\begin{array}{l}\mathrm{H}_{2} \mathrm{O} \\
\mathrm{CH}_{3} \mathrm{COOH}, \\
\text { CTAB, SDS }\end{array}$ & $\mathrm{HU}$ & $1-5 \mathrm{~h}$ at $80^{\circ} \mathrm{C}$ & nanostars, $40-90 \mathrm{~nm}$ & [16] \\
\hline $\mathrm{Pb}$ acetate & $\begin{array}{l}\mathrm{S} \text { in TOP, } \\
\text { ODE, OLA }\end{array}$ & ODE, OA & HI & $\begin{array}{l}\text { injection and } 1-15 \mathrm{~min} \\
\text { growth at } 200^{\circ} \mathrm{C}\end{array}$ & $\begin{array}{l}\text { nanocubes, nanorods, } \\
\text { nanowires }\end{array}$ & [34] \\
\hline $\mathrm{PbO}$ & $\mathrm{S}$ in ODE & $\begin{array}{l}\text { OA, OLA, } \\
\text { ODE }\end{array}$ & HI & $\begin{array}{l}\text { injection and } 1-5 \mathrm{~min} \\
\text { growth at } 210^{\circ} \mathrm{C}\end{array}$ & $10-80 \mathrm{~nm}$, nanocubes & [17] \\
\hline $\mathrm{Pb}$ acetate & Thioacetamide & $\begin{array}{l}\mathrm{OA}, \mathrm{TOP} \\
\mathrm{Ph}_{2} \mathrm{O}, \mathrm{DMF}, \\
\text { chloroalkanes }\end{array}$ & $\mathrm{HU}$ & $1-3 \mathrm{~min}$ at $150-250^{\circ} \mathrm{C}$ & $\begin{array}{l}\text { nanosheets, } \\
3 \mathrm{~nm} \text { thick }\end{array}$ & [22] \\
\hline $\mathrm{PbHal}_{2}$ & $\mathrm{~S}\left(\mathrm{SiMe}_{3}\right)_{2}$ & OLA & $\mathrm{HU}$ & $15 \mathrm{~min}$ at $30-150^{\circ} \mathrm{C}$ & dots, $2-5 \mathrm{~nm}$ & [20] \\
\hline $\mathrm{Pb}$ oleate & $\begin{array}{l}\text { Substituted } \\
\text { thiourea salts }\end{array}$ & $\begin{array}{l}\text { 1-octene, } \\
\text { diglyme }\end{array}$ & $\mathrm{HI}$ & $\begin{array}{l}\text { injection and } 1 \mathrm{~min} \\
\text { growth at } 95{ }^{\circ} \mathrm{C}\end{array}$ & dots, $3-7 \mathrm{~nm}$ & [23] \\
\hline $\begin{array}{l}\mathrm{Pb} \\
\text { octadecylxanthate } \\
(\mathrm{Pb} \text { acetate, } \\
\left.\mathrm{PbCl}_{2} \text { additives }\right)\end{array}$ & & $\begin{array}{l}\text { TOA (TEA, } \\
\text { TDA } \\
\text { additives) }\end{array}$ & $\mathrm{HU}$ & $0.1-24 \mathrm{~h}$ at $80^{\circ} \mathrm{C}$ & $\begin{array}{l}\text { nanoplatelets, } \\
2 \mathrm{~nm} \text { thick, } \\
26 \times 6-118 \times 11 \mathrm{~nm}^{2}\end{array}$ & [21] \\
\hline
\end{tabular}


(A)

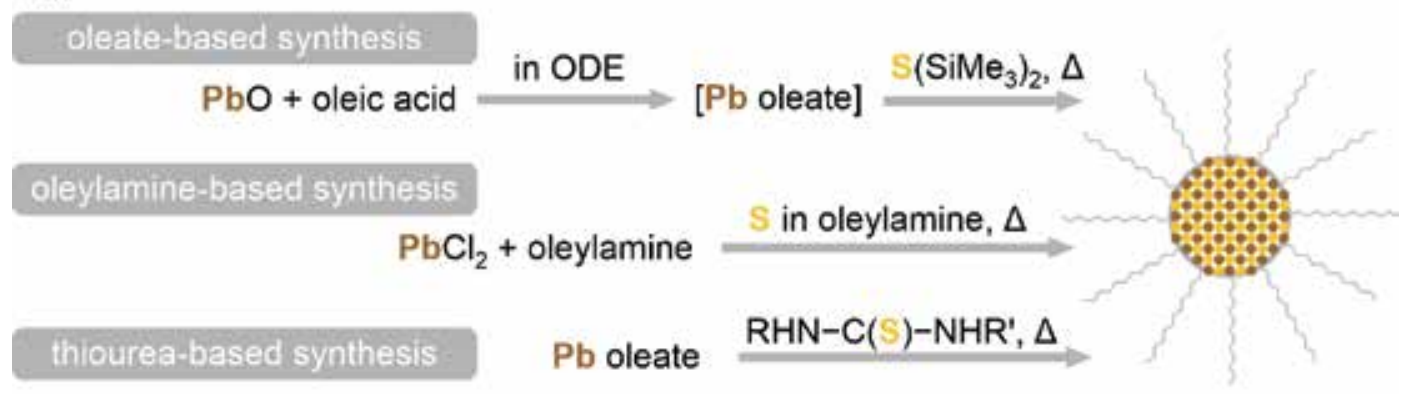

Fig. 2. (A) Reaction schematics of common synthetic methods of $\mathrm{PbS}$ quantum dot nanocrystals. $(B, C)$ TEM images of PbS nanocrystals, illustrating excellent size and shape control. ${ }^{[16-19,21-23]}$

(B)
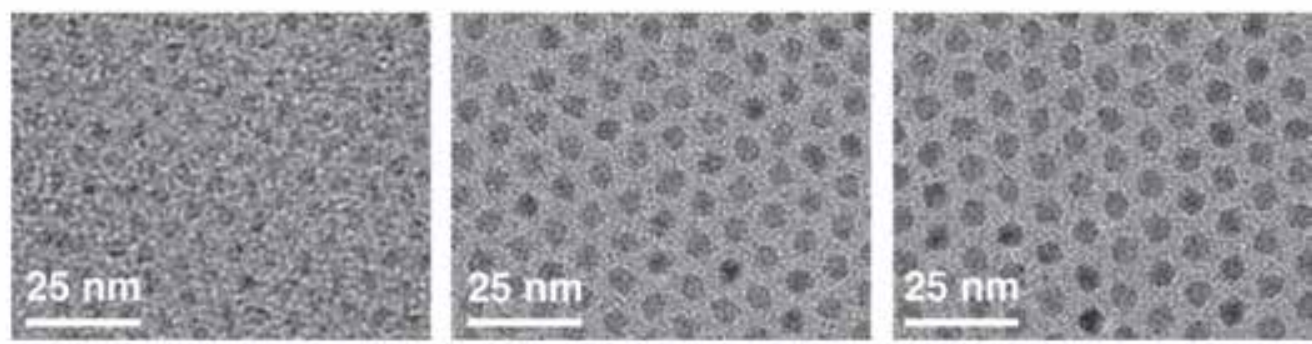

Size control

(C)

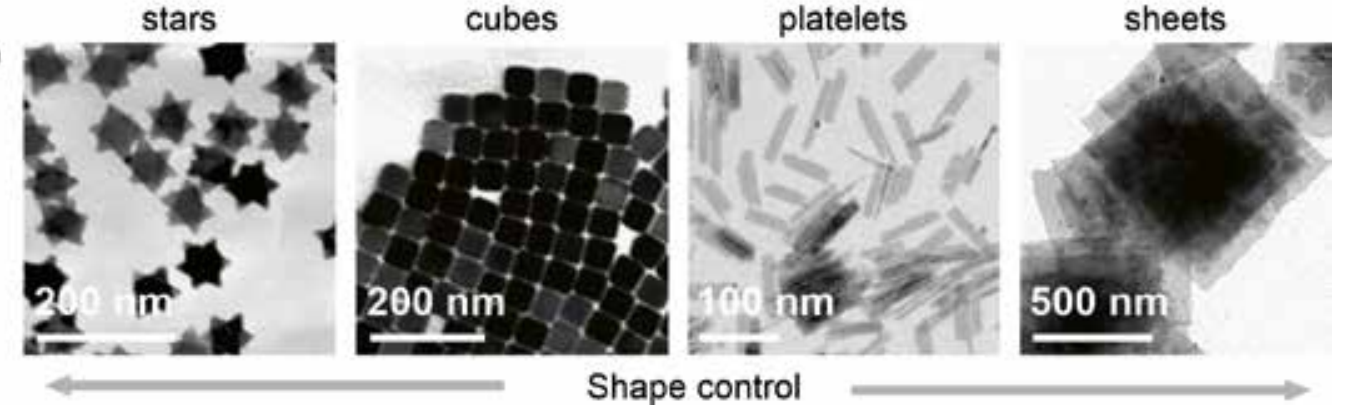

Shrestha et al. studied the influence of process temperatures and found that the size of $\mathrm{PbS}$ nanocrystals is defined by growth temperature. In particular, the authors prepared ultra-small $\mathrm{PbS}$ nanocrystals; by tuning the growth temperature from 5 to $110^{\circ} \mathrm{C}$ the $\mathrm{PbS}$ excitonic peak is tuned between 550 and $800 \mathrm{~nm} \cdot{ }^{[14]}$ Lee at el. aimed to achieve larger $\mathrm{PbS}$ nanocrystals while keeping narrow size distributions $<5 \%$. For this purpose, the authors performed multiple injections of diluted $S$ precursor over the course of 1 hour after the nucleation of $\mathrm{PbS}$ nanocrystals. The concentration of $\mathrm{S}$ precursor was kept below the nucleation barrier, enabling extended growth of nanocrystals. Using this approach, Lee et al. were able to prepare $\mathrm{PbS}$ nanocrystals as large as $9.6 \mathrm{~nm}$ that exhibit sharp excitonic peaks up to $2000 \mathrm{~nm} .{ }^{[15]}$ The luminescence quantum yield of the $\mathrm{PbS}$ nanocrystals can be improved by adding tri-n-octylphosphine to the reaction flask. ${ }^{[26]}$ Creating smaller $\mathrm{PbS}$ nanocrystals and improved size distribution can be achieved by promoting nucleation with high-pKa amine additives.[27] Sargent and co-workers reported systematically better quality $\mathrm{PbS}$ nanocrystals when $\mathrm{Pb}$ oleate solution was refluxed overnight to remove water byproduct completely. [28]

Yarema et al. developed a generalized underpressuregovern-ed scaling-up methodology for hot-injection synthetic approaches, which also works for oleate-based synthesis of $\mathrm{PbS}$ nanocrystals. Applying a mild vacuum to the reaction flask prior the injection of S precursor, large injection volumes can be injected within few seconds (Fig. 3). Importantly, the quality of $\mathrm{PbS}$ nanocrystals (i.e. size, size distribution, size tunability, optical properties, etc.) is maintained while the chemical yield is increased by 1-2 orders of magnitude. [29]

\section{Oleylamine-based Synthesis}

Oleylamine is a common coordinating solvent in colloidal synthesis. ${ }^{[31]}$ Use of oleylamine brings several benefits for the $\mathrm{PbS}$ system, such as high solubility of metal halide precursors and elemental chalcogens, ability to form intermediate complexes with lead salts, and its mildly-reducing properties at high reaction temperatures. The drawback of oleylamine is, however, its weak coordination of the $\mathrm{PbS}$ surface, which leads to surface oxidation during the purification of nanocrystals.

High-quality $\mathrm{PbS}$ nanocrystals can be prepared by using oleylamine for both reaction and injection mixtures containing $\mathrm{PbCl}_{2}$ and elemental $\mathrm{S}$, respectively. ${ }^{[19]}$ The concentration of $\mathrm{PbCl}_{2}$ solution in oleylamine is kept very high, enabling fast nucleation and high degree of $\mathrm{PbS}$ supersaturation at a moderate growth temperature of $80{ }^{\circ} \mathrm{C}$. The oleylamine-based synthesis was first reported by Cademartiri et al. and it is the second most-common recipe for monodisperse $\mathrm{PbS}$ nanocrystals. ${ }^{[19]}$ Although initially limited in achievable sizes, ${ }^{[19]}$ the oleylamine-based synthesis was modified by Moreels et al..$^{[32]}$ and Zhang et al., ${ }^{[20]}$ expanding the band gap tunability to $750-1700 \mathrm{~nm}$ wavelength range. The latter paper reports a non-injection heating-up modification of oleylamine-based synthesis, employing bis(trimethylsilyl)sulfide as the $\mathrm{S}$ precursor. This method enabled easy scalability, while the size distributions remain comparable to hot-injection methods $(\sigma \sim 7-10 \%))^{[20]}$ Synthesis using larger excess of $\mathrm{PbCl}_{2}$ can lead to thin shells of $\mathrm{PbCl}_{\mathrm{x}}$ surrounding the $\mathrm{PbS} \mathrm{NC}$. Winslow et al..$^{[33]}$ used small-angle neutron scattering (SANS) to measure the $\mathrm{PbCl}_{\mathrm{x}}$ shells. Due to the isolating shells these NCs are not suited for application where charger transport is crucial (e.g. solar cells), but they are more stable and therefore well suited for luminescence applications. 

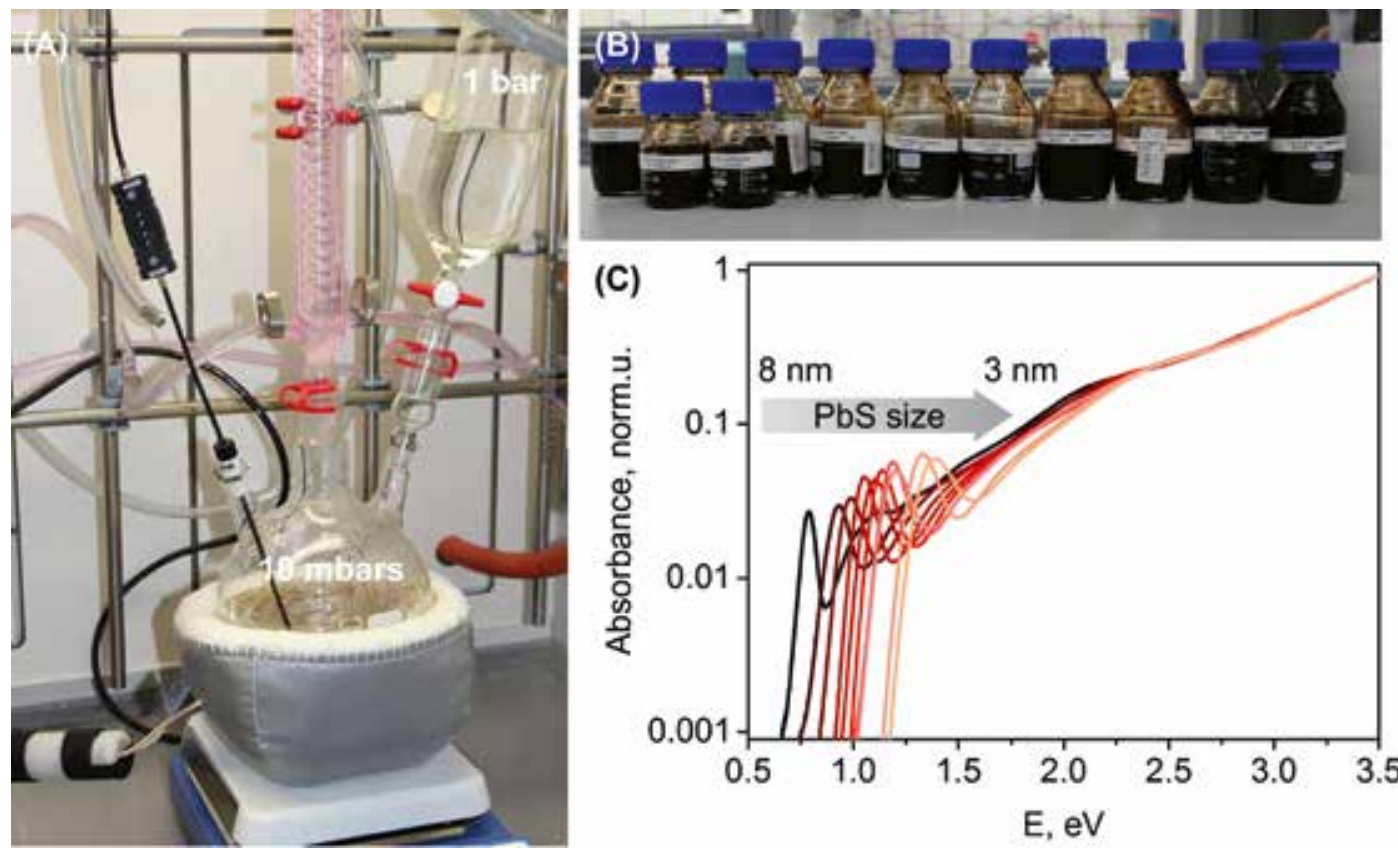

Fig. 3. (A) Photograph of underpressure-governed hotinjection laboratory setup. (B) Multigram-scale colloidal solution of $\mathrm{PbS}$ nanocrystals, prepared by the underpressure-governed hot-

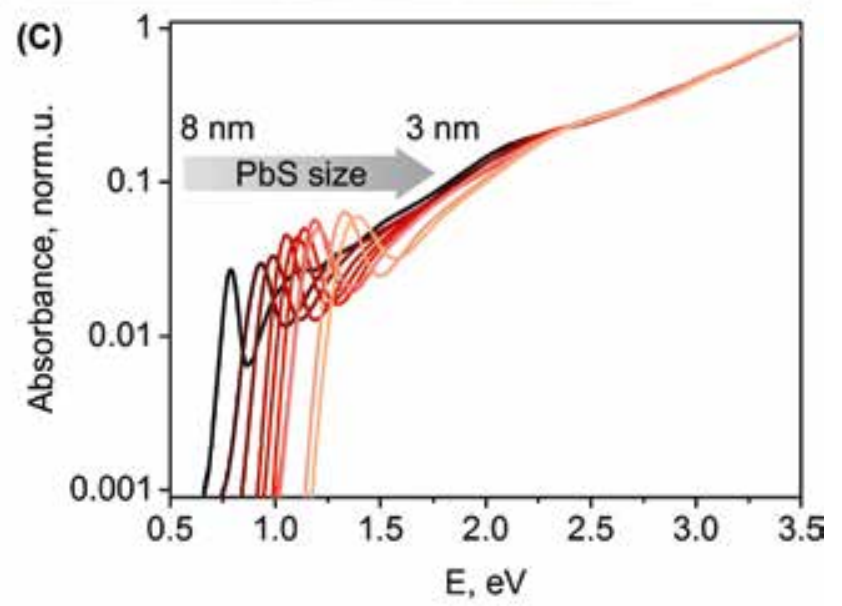
injection, and (C) their absorption spectra. ${ }^{[29,30]}$

Another peculiarity of oleylamine-based synthesis is that $\mathrm{Pb}$ precursor is present in multifold excess (compared to the $\mathrm{S}$ precursor). ${ }^{[19]}$ The non-equimolar precursor ratios (i.e. [Pb] $>$ [S]) are used to achieve better size distributions of $\mathrm{PbS}$ nanocrystals, due to highly-suppressed Oswald ripening mass transfer of $\mathrm{S}$ atoms. Weidman et al. studied the influence of $\mathrm{Pb} / \mathrm{S}$ precursor ratio and were able to achieve highly monodisperse $\mathrm{PbS}$ nanocrystals $(\sigma \sim 3.3 \%)$, outstandingly narrow absorption peaks, and long-term air-stability of $\mathrm{PbS}$ nanocrystals..$^{[13]}$

\section{Other Synthetic Approaches}

Although oleate-based and oleylamine-based recipes provide high-quality $\mathrm{PbS}$ nanocrystals, these methods do have some limits and drawbacks. For example, the size range is limited to $<10 \mathrm{~nm}$, shape control is absent, a malodorous sulfur precursor is used, and the approach results in incomplete chemical yield (i.e. excess of $\mathrm{Pb}$ precursor). In order to tackle these problems, alternative synthetic approaches for PbS nanocrystals were developed.

Hendricks et al. employed alkyl-derivatives of thiourea as $\mathrm{S}$ precursors. Depending on hydrocarbon side chain, the reactivity of these precursors can be tuned over 5 orders of magnitude, resulting in accurate size control and high chemical yield for monodisperse $\mathrm{PbS}$ nanocrystals. ${ }^{[23]}$

Anisotropic growth of $\mathrm{PbS}$ nanocrystals is achieved by combining several surfactants ( $\mathrm{PbS}$ nanorods or nanowires) ${ }^{[34]}$ or by using organic additives (i.e. 1,2-dichloroethane for $\mathrm{PbS}$ nanosheets). [22] $\mathrm{PbS}$ nanoplatelets can be prepared by thermal decomposition of single-source $\mathrm{Pb}$-alkylxanthate precursor, while lateral dimensions are tuned by ternary alkylamine additives. ${ }^{[21]}$ Larger sizes of PbS nanocrystals with controlled morphology are typically achieved by water-phase synthetic approaches. ${ }^{[16,35]}$

\section{Purification of As-synthesized PbS Nanocrystals}

A typical liquid-phase synthesis of nanocrystals ends by rapid reaction termination, which is achieved by cooling the reaction flask to room temperature. The obtained crude solution contains large amounts of organic solvents and ligands as well as by-products and unreacted precursors. For any further use, it is necessary to separate nanocrystals from excessive organic molecules, using established purification protocols.

The purification or 'washing' process is based on limited solubility of nanocrystals in polar solvents and is carried out using polar-nonpolar, co-solvent systems. ${ }^{[36]}$ With the addition of a polar solvent (the 'antisolvent'), nanocrystals coalesce, while the organic molecules remain soluble. Nanocrystals are then precipitated by a short, high-speed centrifugation step, the solvents and organics are disposed, and the nanocrystals are redissolved.

It is extremely important to standardize the 'washing' process. For example, a simple step such as whether one wipes away excess organics that may stick to the centrifuge tube before re-addition of a non-polar solvent can ultimately impact nanocrystal surface quality and device performance.

During each purification cycle, excess ligands and solvents are gradually removed. If purification is extended, the ligands, which are bound to the surface, can also be partially displaced. This is, however, unwanted, since missing ligands enable other processes such as surface oxidation. ${ }^{[37]}$ The number of washing cycles should be stopped when the ligand coverage of nanocrystal surface becomes stable (around 3-4 $\mathrm{nm}^{-2}$ for $\mathrm{PbS}$ nanocrystals). ${ }^{[29,32]}$

The choice of antisolvent is highly important. For example, several studies show the detrimental effect of protic antisolvents (i.e. alcohols) during the purification of $\mathrm{PbS}$ and other nanocrystals. ${ }^{[38,39]}$ Kirmani et al. showed that methanol can strip off up to $80 \%$ of ligands from thin-film of oleic-acid-coated $\mathrm{PbS}$ nanocrystals. At identical conditions, aprotic acetonitrile retains the oleate ligand shell almost completely. ${ }^{[38]}$ These results can be associated with the ability of alcohols to protonate oleate ligands, which can then be desorbed as neutral oleic acid species. ${ }^{[37]}$

After purification, 'clean' samples comprise stable colloidal solutions of oleate-covered $\mathrm{PbS}$ nanocrystals, dispersed in hexane or toluene. Prior to inclusion in a device, where the $\mathrm{PbS}$ layer is expected to electrically conduct, such samples should undergo a post-synthetic treatment, during which the oleate shell is replaced with shorter organic of fully-inorganic ligands. As will be discussed in Section 3, this ligand-exchange process can be carried out either in solution or on already formed solid nanocrystal-constituent thin films.

\section{Step 2: Characterization of PbS Quantum Dot Nanocrystals}

Prior to assembly into thin films, a number of properties should be examined and considered including the morphology of $\mathrm{PbS}$ nanocrystals (i.e. size, shape, size uniformity), their structure (i.e. composition, surface, ligand type and coverage). ${ }^{[40,41]}$ Fig. 4 highlights some common methods. 

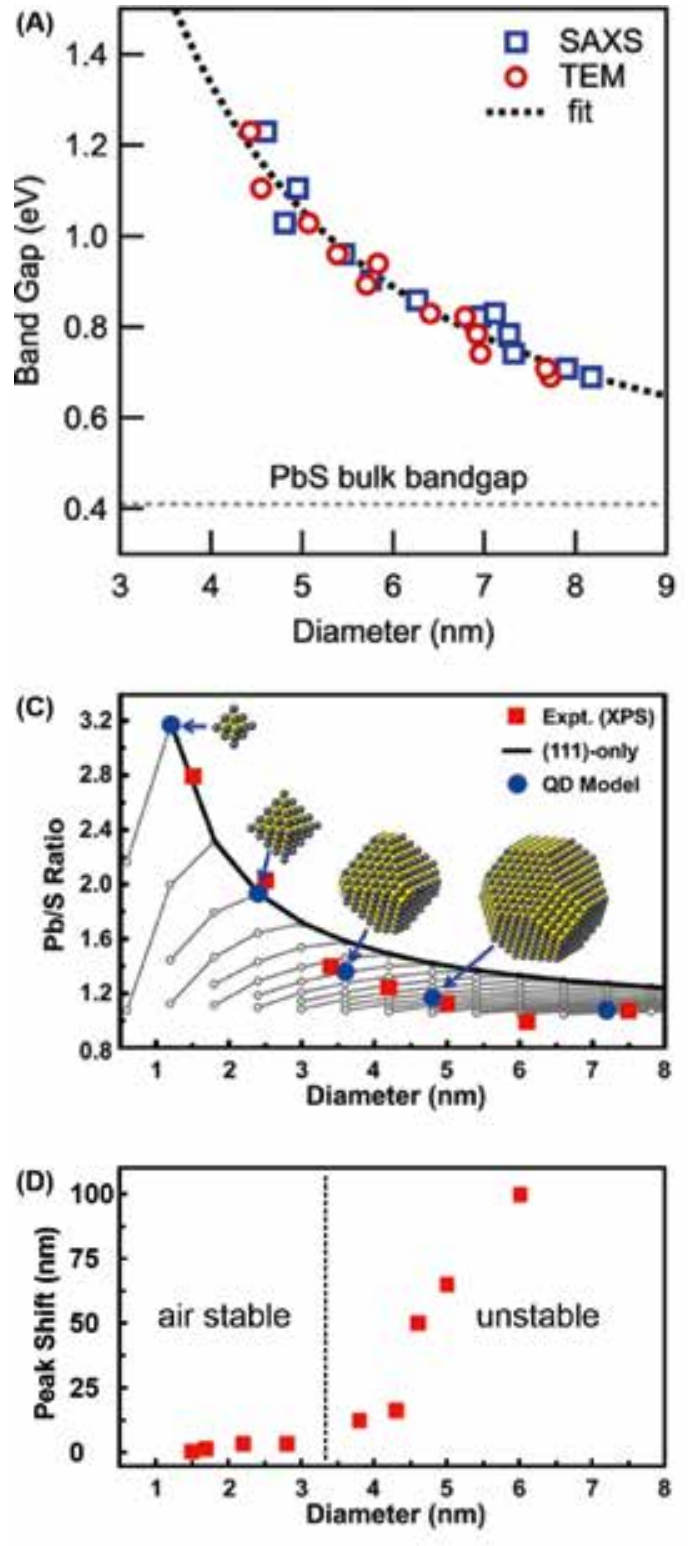
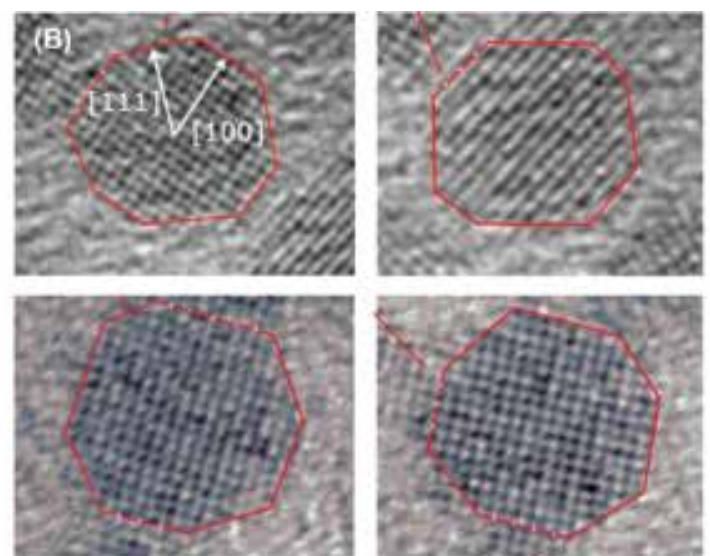

(E)
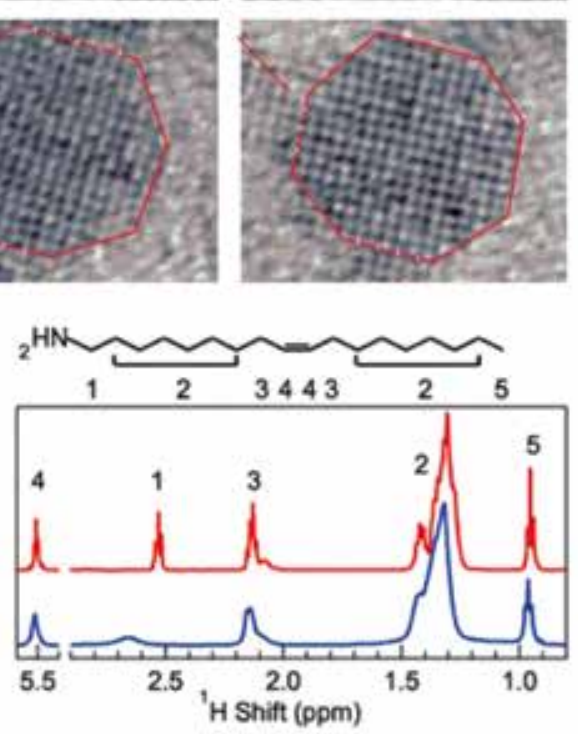

(F)

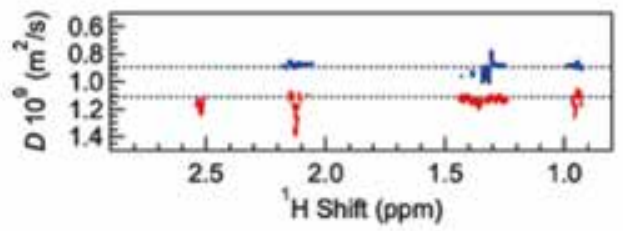

(G)

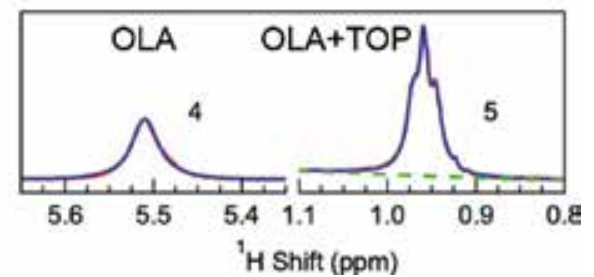

Fig. 4. Characterization of PbS nanocrystals. (A) Sizedependent band gap of $\mathrm{PbS}$ nanocrystals, extracted from SAXS and TEM measurements. (B) High-resolution TEM images of cubooctahedral PbS nanocrystals. (C) Composition of $\mathrm{PbS}$ nanocrystals, measured by XPS and calculated for cubooctaherdal shapes with different ratios of (111) and (100) surfaces, as a function of size. (D) Shift of first excitonic peak during 12 weeks of storage in ambient, as a function of $\mathrm{PbS}$ size. (E) Proton NMR spectra of free oleylamine (red) and bound to the PbS surface (blue). (F) DOSY spectrum of free and bound oleylamine. (G) Quantitative proton NMR reveals a ratio between oleylamine and tri-noctylphosphine, calculating ratio of alkene and methyl protons. . $11,13,25,32]^{2}$

\section{Nanocrystal Morphology}

The shape of $\mathrm{PbS}$ nanocrystals is most often determined from TEM images where it is possible to visually distinguish between shapes (such as spheres, cubes, rod, platelets, or sheets) or to quantify the shape inhomogeneity, if several shapes are present. ${ }^{[11]}$ While shape of $\mathrm{PbS}$ quantum dots is often approximated to be a sphere, the actual morphology is highly faceted (Fig. 4B). In fact, the shape of $\mathrm{PbS}$ nanocrystals can be best described by a cuboctahedron (i.e. an octahedron with truncated vertices, virtually forming a cube). The surface of $\mathrm{PbS}$ nanocrystals thus consists of two types of surfaces: (100) with stoichiometric cubic arrangement of $\mathrm{Pb}$ and $\mathrm{S}$ atoms and $\mathrm{Pb}$-rich (111) with hexagonal arrangement of $\mathrm{Pb}$ atoms. ${ }^{[11]}$ The ratio between surface areas of (111) and (100) is called the Wulff ratio and is an important parameter, which influences oxidation stability of $\mathrm{PbS}$ nanocrystals and the performance of $\mathrm{PbS}$-based devices. ${ }^{[10,42]}$

Three experimental techniques are often used to measure size and size distribution of nanocrystals: transmission electron microscopy (TEM), small-angle X-ray scattering (SAXS), and optical absorption spectroscopy.

TEM analysis is the most-direct method to measure size and size distribution of nanocrystals. A drawback of TEM is its small sampling area (i.e. size is typically measured locally for a limited number of nanocrystals).
From SAXS spectra of diluted colloidal solutions, both average size and size distribution can be extracted from the large sample size. ${ }^{[43]}$ SAXS spectra are sensitive to non-spherical shapes; ${ }^{[44]}$ however, it is important to keep in mind that SAXS results describe an average nanocrystal. Also, the ligand shell layer and surface of nanocrystals are 'smeared', which often leads to size overestimation. ${ }^{[13]}$ Ideally, both SAXS and TEM are combined to determine size and size distribution of $\mathrm{PbS}$ nanocrystals (Fig. 4A). ${ }^{[13]}$

Combining absorption spectroscopy with TEM and SAXS, a dependence between optical band gap and a size of nanocrystals can be reliably defined (Fig. 4A). This introduces a very handy approach to estimate a size of nanocrystals. ${ }^{[45]}$ Taking the position of the first excitonic peak as the optical band gap, $E_{g, N C}$, the average size of $\mathrm{PbS}$ nanocrystals, $d$, can be estimated ${ }^{g, N C}$ ia the relation:

$$
E_{g, N C}=E_{g, b u l k}+\frac{1}{0.0392 d^{2}+0.114 d}
$$

where $E_{g, b u l k}$ of $\mathrm{PbS}$ is $0.41 \mathrm{eV} ; E_{g, N C}$ in $\mathrm{eV}$; $d$ in nm. ${ }^{[13]}$ Kang et al. calculate the relation between optical band gap and nanocrystals size using theoretical calculations of the electronic structure of spherical $\mathrm{PbS}$ with a four-band envelope-function formalism that agrees with the measured values. ${ }^{[46]}$ Weidman et al. further derived 
a polynomial relation between width of first excitonic peak and size distribution of PbS nanocrystals. ${ }^{[13]}$

The morphology of nanocrystals is important for device performance because there is size-dependent mobility due to the sizedependence of electronic coupling (which also depends on shape and facet orientation) and size-dependent reorganization energy. ${ }^{[47]}$

\section{Composition of Nanocrystals}

While $\mathrm{PbS}$ is a binary semiconductor, as a nanocrystal, it can easily be non-stoichiometric due to the presence of Pb-rich (111) surfaces, which leads to $\mathrm{Pb}: \mathrm{S}$ atomic ratios $>1 .{ }^{[45,48]}$ Additionally, it is possible to dope $\mathrm{PbS}$ by adding the dopant precursor (e.g. bismuth acetate for bismuth) to the lead precursor. ${ }^{[49]}$

Composition of nanocrystals can be measured by a number of techniques, including inductively coupled plasma atomic emission spectrometry (ICP) and energy dispersive X-ray (EDX) spectroscopy. For $\mathrm{PbS}$, however, the $\mathrm{Pb} \mathrm{M}$ and $\mathrm{S} \mathrm{K}$ lines overlap rendering EDX spectroscopy useless for distinguishing the $\mathrm{Pb}: \mathrm{S}$ atomic ratio. Instead X-ray photoelectron spectroscopy (XPS) can be used to determine the $\mathrm{Pb}$ to $\mathrm{S}$ ratio. For example, Fig. 4C (red squares) shows an example dependence of $\mathrm{PbS}$ stoichiometry as a function of $\mathrm{PbS}$ diameter. ${ }^{[48]} \mathrm{The} \mathrm{Pb}: \mathrm{S}$ atomic ratio stays $>1$ for the entire size range and smoothly increases as the size of nanocrystals decreases. Very small $\mathrm{PbS}$ nanocrystals (i.e. $d<2 \mathrm{~nm}$ ) exhibit highly non-stoichiometric compositions with $\mathrm{Pb}: \mathrm{S}>2$, due to contributions of Pb-rich (111) surfaces. Choi et al. combined size-dependent composition measurements (XPS) with theoretical calculations for $\mathrm{PbS}$ nanocrystals of cubooctahedral shape with variable Wulff ratios (Fig. 4C). In particular, authors figured out that the smallest $\mathrm{PbS}$ nanocrystals have only (111) surfaces (i.e. octahedral shape), while bigger $\mathrm{PbS}$ nanocrystals $(\mathrm{d}>3.5 \mathrm{~nm})$ are cubooctahedrons with minority of (100) surfaces.

Importantly, the surface and stoichiometry can be linked to device performance. For example, Choi et al. (Fig. 4D) found that small octahedral $\mathrm{PbS}$ nanocrystals are stable in ambient conditions while larger cubooctahedral $\mathrm{PbS}$ nanocrystals degrade over time due to oxidation of (100) surfaces. ${ }^{[48]}$ Work by Yazdani et al. showed that non-stoichiometry leads to charge imbalance and doping of nanocrystal solids, that can be oxidized or reduced and form electronic traps in nanocrystal solids. ${ }^{[47]}$ Balazs et al. used stoichiometry control to improve the hole mobility.

The surface termination, i.e. the ligand coverage of the individual nanocrystals, can influence the final device performance as it impacts the quality of the ligand exchange, the thin film packing density and crystallographic orientation. ${ }^{[50,51]}$ Fourier-Transform Infrared (FTIR) spectroscopy and Nuclear Magnetic Resonance (NMR) techniques ${ }^{[20,32]}$ can be used to distinguish between unbonded and bonded surface atom or molecule. To take an NMR study of oleylamine-covered $\mathrm{PbS}$ nanocrystals as an example, a $\mathrm{PbS}$ sample was compared with oleylamine reference solution (Fig. 4E,F). ${ }^{[32]}$ A conventional proton NMR spectrum of the $\mathrm{PbS}$ sample shows broadening of all oleylamine resonances, suggesting that oleylamine is bonded to the nanocrystal surface, which restricts the rotational motion of molecules. Diffusion Ordered Spectroscopy (DOSY) estimates that the diffusion coefficient of bonded oleylamine ligands is reduced in comparison with free oleylamine reference by $20 \%$. The NMR methods can be quantitative. For example, by integrating resonances from alkene and methyl protons, it is possible to deduce a ratio between oleylamine and tri-noctylphosphine ligands (Fig. 4G). ${ }^{[32]}$

\section{Step 3: Fabrication of Thin Films from PbS Quantum Dot Nanocrystals}

After synthesis, the $\mathrm{PbS}$ nanocrystals are covered with longchain organic molecules (e.g. oleate ligands), which stabilize the nanocrystals in nonpolar solvents. Such long-term stable colloidal suspensions (ink solutions) are convenient starting materials for the thin-film fabrication step; however, the long ligands hinder charge transport and make the resulting films insulating. ${ }^{[38]}$ Hence, the original ligands are replaced via the so-called ligand-exchange process, which can be carried out either prior to the deposition of nanocrystals (i.e. in solution) or already on the thin film (i.e. in solid-state). Fig. 5 schematically illustrates the fabrication process of $\mathrm{PbS}$ quantum dot solids.

In addition to controlling the interparticle distance and thus the carrier mobility in the thin film, ${ }^{[52]}$ the ligand shell modifies the electronic properties of nanocrystal thin films including the positions of the highest occupied and lowest unoccupied states which make up the valence and conduction band. By contributing to dipoles, they can shift the Fermi energy. ${ }^{[53]}$

Different fabrication methods can be chosen to match the fabrication requirements of the device and obtain the desired properties of the resulting nanocrystal thin film. For example, the film thickness can be as small as a single monolayer of $\mathrm{PbS}$ nanocrystals (using dip coating or Langmuir-Blodgett method) ${ }^{[54]}$ or in micrometer-range thickness (using spray coating or blade-coating). ${ }^{[55]}$ For most $\mathrm{PbS}$ nanocrystal devices, film thickness ranges from tens to hundreds of nanometers, which can be achieved by spin-coating. ${ }^{[7,56]}$ If non-continuous layers of $\mathrm{PbS}$ nanocrystals are required, methods such as inkjetprinting, ${ }^{[57]}$ stamping, ${ }^{[58]}$ etching, ${ }^{[59]}$ patterning and lift-off, ${ }^{[60]}$ etc. can be utilized.

Finally, PbS nanocrystal thin films may undergo postdeposition treatment. Annealing at moderate temperatures is often used to remove volatile solvent and ligand molecules, whereas high-temperature annealing leads to the sintering of $\mathrm{PbS}$ nanocrystal films. In order to increase the device stability, $\mathrm{PbS}$ nanocrystals may be protected by a capping layer or by infilling the interparticle voids with $\mathrm{ALD}^{[61-63]}$ or chemical bath deposition. ${ }^{[64]}$

\section{Preparing the Thin Film Fabrication}

Among important properties of $\mathrm{PbS}$ inks are concentration of nanocrystals, volatility of solvent, and viscosity of colloidal suspension. Choosing the right solvent (or solvent mixture) and optimal concentration of $\mathrm{PbS}$ nanocrystal is key for achieving a high-quality thin film. In addition, the environment during the thin film fabrication is of special importance. Temperature of the fabrication process, vapor pressure, humidity, and oxygen content will have a notable impact either on rheological properties of $\mathrm{PbS}$ nanocrystal inks or on properties of obtained quantum dot solids. ${ }^{[65]}$

For example, $\mathrm{PbS}$ quantum dot solar cells, fabricated at ambient conditions, exhibit systematically higher efficiencies than those prepared under air-free conditions, due to the lack of oxygen doping. ${ }^{[66]}$ Furthermore, solar cell performance improves after a few days of air exposure. ${ }^{[67]}$ Gao et al. ${ }^{[68]}$ explained this phenomenon by the formation of $\mathrm{PbO}$ and $\mathrm{PbOH}$ surface species, which allows for better energy band alignment with the electron transport layer and therefore better charge extraction.

\section{Solid-state Ligand Exchange}

A solid-state ligand-exchange process aims to replace or remove insulating organic monolayer around nanocrystals ${ }^{[56]}$ following deposition of the nanocrystal solid (Fig. 5A). Typically, $\mathrm{PbS}$ thin films are soaked in (or dipped into) a solution, which contains molecules with stronger binding affinity to the $\mathrm{PbS}$ surface than the native ligands. The ligands used for this purpose can be split in two groups: (i) short-chain organic molecules, and (ii) compounds, providing atomic or short anionic passivation shell. Among organic molecules, alkyl dithiols (e.g. 1,2-ethanedithiol, 
1,4-benzenedithiol, etc.) are often used due to robust $\mathrm{Pb}-\mathrm{S}$ bonding and chelating properties of these molecules. ${ }^{[69]}$ The second group of reagents can be represented with tetrabutylammonium iodide (TBAI) ${ }^{[42]}$ or ammonium thiocyanate $\left(\mathrm{NH}_{4} \mathrm{SCN}\right),{ }^{[70]}$ which are able to passivate the surface of $\mathrm{PbS}$ nanocrystals with $\mathrm{I}^{-}$and $\mathrm{SCN}^{-}$ ions, respectively (Fig. 5B).

A solid-state ligand exchange renders a thin film of $\mathrm{PbS}$ nanocrystals insoluble in the original nonpolar solvents, thus enabling a deposition of subsequent layers of $\mathrm{PbS}$ nanocrystal inks. A solid-state ligand exchange is thus compatible with layerby-layer build-up of nanocrystal solids, and the thickness of such films can be controlled with a single monolayer precision. ${ }^{[71]}$

With the new ligand shell, the interparticle distance is reduced, which is beneficial for conduction but leads to volume shrinkage and formation of cracks. ${ }^{[71]}$ The cracks tend to propagate through the film if the thickness of $\mathrm{PbS}$ layer exceeds a few tens of nanometers per deposition step. The crack formation limits the applicability of traditional solid-state ligand exchange to rather thin, $<300 \mathrm{~nm}$ layers of nanocrystal solids.[71-73] $\mathrm{Lu}$ et al. ${ }^{[74]}$ demonstrated a modified procedure by controlling the NCs packing order and careful selection of solvents, that enables the one-step solid-state ligand exchanged crack-free films up to $1 \mu \mathrm{m}$ thickness.

Furthermore, it is important to note that the nanocrystal solid is affected by the solvent used for the ligand-exchange reaction. For example, smaller interparticle distance was reported when acetonitrile was replaced with methanol. This was attributed to mild removal of oleic acid by methanol.[38] The speed of the ligand exchange influences the ligand coverage. A too fast exchange can lead to NC aggregates and ligand-free surfaces. ${ }^{[75]}$ Using less volatile solvents can reduce the ligand exchange speed and improve ordering as well as ligand coverage.

\section{Solution-phase Ligand Exchange}

The organic shell of $\mathrm{PbS}$ nanocrystals can alternatively be replaced by shorter molecules or ions in solution phase, preceding the thin film deposition step (Fig. 5A). During the last decade, there have been many reagents tested for solution-phase ligand exchange and a treatment with inorganic salts results in effective removal of organic molecules. The all-inorganic $\mathrm{PbS}$ nanocrystals are then stabilized by electrostatic field (i.e. the surface of nanocrystals is changed). Among first examples, short hydrazinium metal-chalcogenide complexes were employed. ${ }^{[76]}$ This procedure was further extended to less toxic ammonium and alkali metal salts of metal-chalcogenide complexes ${ }^{[77]}$ as well as to simple chalcogenide and hydrogenchalcogenide salts. ${ }^{78]}$ Recently, short halide molecules were used to passivate surfaces of $\mathrm{PbS}$ nanocrystals with halide ions, such as $\mathrm{CdCl}_{2}, \mathrm{PbI}_{2}, \mathrm{NH}_{4} \mathrm{I}$, $\mathrm{KI}_{3}$, Li halides, etc. (Fig. 5C). ${ }^{[7-82]}$ This was found to improve airstability of $\mathrm{PbS}$ nanocrystals due to saturation of (100) surfaces $^{[83]}$ or complete surface passivation. ${ }^{[42]}$ The method is now extended to pseudohalide (i.e. $\mathrm{NaN}_{3}, \mathrm{KSeCN}$ ) and halometallate ligands (i.e. $\left.\mathrm{CH}_{3} \mathrm{NH}_{3} \mathrm{PbI}_{3}\right) \cdot{ }^{[80,84,85]}$

Solution-phase ligand exchange can overcome the typical problems of nanocrystal solids, prepared via the solid-state ligand exchange approach. Specifically, thick $\mathrm{PbS}$ layers can be deposited from concentrated inks by a fast, single deposition step. These films are characterized by homogeneously replaced ligands throughout the film and by absence of cracks. As the prepared inks can be blended, mixed nanocrystal layers can be prepared, with properties that could not be achieved by solid state ligand exchange (e.g. mixed $n$-type and $p$-type nanocrystal layer). ${ }^{\left[{ }^{[6]}\right.} \mathrm{At}$ the same time, the solution-phase ligand exchange approach is difficult to adapt to multistep deposition, which limits the overall thickness and the thickness control.

Interestingly, due to the use of orthogonal solvents, solutionphase and solid-state ligand exchange approaches can be combined. In fact, high-performing $\mathrm{PbS}$ quantum dot solar cells often use the

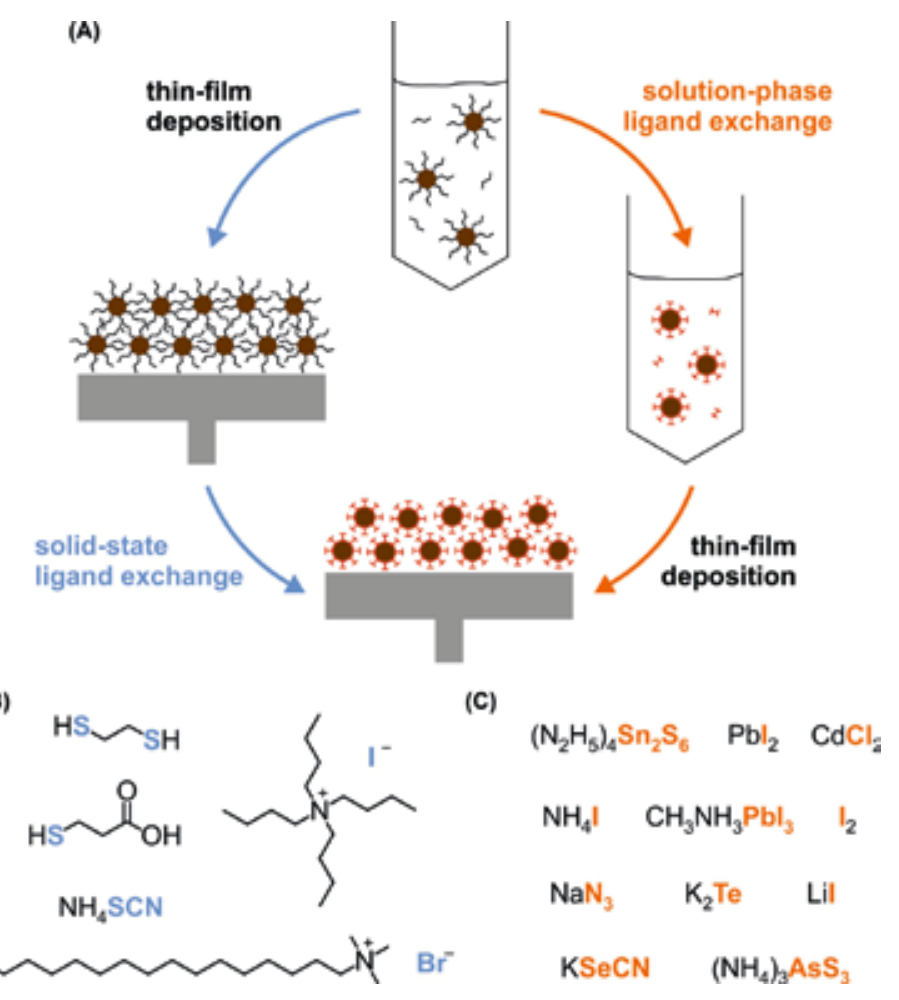

Fig. 5. (A) Schematics for deposition of nanocrystal-based thin films, including a ligand-exchange step in solution or in solid state. $(B, C)$ List of chemicals used for solid-state (B) and solution-phase (C) ligand exchange reaction.

two ligand exchange methods for two subsequent $\mathrm{PbS}$ layers in its structure. ${ }^{[7]}$ First, a solution-phase ligand exchange is employed to create halide-covered $\mathrm{PbS}$ nanocrystal ink. This ink is then spincoated in a single step creating a thick layer $(350 \mathrm{~nm})$. Second, two layers of EDT PbS nanocrystals (for a total thickness of $65 \mathrm{~nm}$ ) were deposited on the initial layer using solid-state ligand exchange.

\section{Blanket-type Deposition Techniques}

Colloidal nanocrystals can be deposited by various methods: rotation-based spin coating, layer-by-layer dip coating, spray deposition and self-metered blade coating are among the most used techniques. High-quality nanocrystal-based solids are characterized by uniform thickness and minimal roughness of thin films as well as low-density of microstructural defects (cracks, rims, pits, etc.) and compositional homogeneity in lateral and depth directions. Each deposition method works for a limited thickness range and provides a different extent of thickness and roughness control. These three characteristics represent a basis for the choice of deposition technique.

Spin coating is one of the most widely adopted solutiondeposition methods (e.g. an essential fabrication step in e-beam and photolithography to prepare a sacrificial polymer layer for lift-off process). During the spin-coating deposition, uniform films are formed by rotating (i.e. spinning) the substrate such that the centrifugal forces counteract the surface tension and thus spread the material homogeneously. Uniform and tunable thicknesses of spin-deposited layers (20-300 nm thick) can be obtained by adjusting the spinning speed and acceleration rate as well as the wetting properties and temperature of substrate. Another promising approach to reduce film roughness is to use a mixture of two solvents with different boiling points, which creates a solvent concentration gradient across the film due to strong Marangoni flow and leads to slower evaporation rates at the edges, thus preventing coffee-stain patterns. ${ }^{[87]}$ Although fast 
and convenient, spin coating is also a rather wasteful process since excessive nanocrystal inks are typically spun off the substrate and cannot be easily recovered. Minimal and maximal thickness of the spin-coated layer are limited by wettability and viscosity of nanocrystal ink, respectively.

Ultrathin layers of nanoparticles can be prepared via the dipcoating deposition approach. For this method, a substrate is inserted (i.e. dipped) into nanocrystal ink and then slowly pulled out of the solution, forming a continuous thin film of nanocrystals. ${ }^{\text {[71] }}$ The dip-coating process is governed either by capillary forces or by viscous drag, depending on the withdrawal trajectory of the substrate and the viscosity of the solvent. ${ }^{[8]}$ The thickness of the dip-coated layer is mainly controlled by the concentration of nanocrystal solution, however, withdrawal speed and angle as well as temperature and viscosity of nanocrystal ink must be considered. ${ }^{[88]}$ Since dip-coating deposition can be optimized to yield a monolayer of $\mathrm{PbS}$ nanocrystals, it provides an accurate thickness control and excellent film homogeneity. In addition, dip coating is almost waste-free as the dipping solutions are typically reused. However, for the dip-coating deposition, the wettability between substrate and nanocrystal ink is much more important (unoptimized wetting properties may result in island-like coverage of $\mathrm{PbS}$ nanocrystals). The dip-coating process becomes time consuming, if relatively thick, $>200 \mathrm{~nm} \mathrm{PbS}$ layers are aimed for.

Spin- and dip-coating are the two most common deposition methods for $\mathrm{PbS}$ nanocrystal thin films, providing a comparable film morphology and device performance. ${ }^{[89]}$ Among other blanket-type deposition methods, spray coating, LangmuirBlodgett and self-metered methods like blade-coating ${ }^{[90]}$ have been employed for $\mathrm{PbS}$ nanocrystal inks. Spray coating allows a deposition on flexible or bent substrates and supports roll-to-roll fabrication. Kramer et al. ${ }^{[91]}$ developed a spray-coating method for $\mathrm{PbS}$ nanocrystal inks and showed that performance of such solar cells is on par with spin-coated devices. Spray coating shows superior sample-to-sample reproducibility, ${ }^{[92]}$ being also suitable for deposition of large area substrates. Langmuir-Blodgett and Langmuir-Schaefer methods are designed to pick up a monolayer of nanocrystals from the water-air interface. ${ }^{[54]}$ Although these methods are precise in controlling thickness, packing density, and conformal coating of non-flat substrates, the presence of water is problematic for $\mathrm{PbS}$ nanocrystals, which are prone to oxidation. [93] Micrometer thicknesses of nanocrystal films can be achieved by convenient blade coating. The main problem of this method is the appearance of cracks due to fast evaporation of the solvent and volume shrinkage. Recently, Fan et al..$^{[55]}$ produced a crackfree blade-coated $\mathrm{PbS}$ layer, owing to precise engineering of the evaporation process via the use of a four-component solvent mixture and elevated temperature of the process.

All blanket-type deposition methods can be repeated on the same film, increasing the overall thickness of the layer. For this purpose, however, the previous $\mathrm{PbS}$ layer should be rigidified either by chemical cross-linking of PbS nanocrystals (i.e. solidstate ligand-exchange process) or by the use of orthogonal solvents. Fig. 6 illustrates a multilayer fabrication of $\mathrm{PbS}$ thin films via dip-, spin-, and spray-coating deposition techniques.

\section{Local-type Deposition Techniques}

Local deposition methods are advantageous over blankettype techniques, enabling effective use of material as well as predetermined position and pattern of the deposited layer. ${ }^{[55]}$ Inkjetprinting is a highly promising local deposition method, which offers multiple deposition steps, single droplet printing (i.e. dropon-demand), parallel processability (i.e. multi-nozzle set-ups), and deposition of materials blends (i.e. all-additive printing). ${ }^{[94,95]}$ The thickness, size, and roughness of inkjet-printed layers can be systematically tuned as a function of nozzle size, temperature of substrate and nozzle, solvent choice, solution concentration, and substrate surface chemistry. Thickness homogeneity of printed layers is commonly achieved by depinning (i.e. increasing the contact angle to $\sim 60-70^{\circ}$ by tuning the wettability of the substrate and viscosity of solution). ${ }^{[55]} \mathrm{PbS}$ nanocrystal layers were inkjetprinted for quantum-dot-based light emitting diodes ${ }^{[96]}$ and for fully-printed infrared photodetectors. ${ }^{[97]}$ Taking an example of the latter work, highly-performing $\mathrm{PbS}$ photodetectors were fabricated with ultralow material and time cost $(0.3 \mathrm{mg}$ of $\mathrm{PbS}$ and $14 \mathrm{~s}$ of fabrication time per device), which was achieved by a pre-programmable printing sequence. ${ }^{[97]}$ This work highlights the benefits of local-type deposition methods in general, and inkjetprinting in particular.

Patterned layers of nanocrystals can also be fabricated by direct optical lithography, ${ }^{[98]}$ template stamping (i.e. contact printing), ${ }^{[58]}$ and Langmuir-Schaefer ${ }^{[99]}$ approaches. The direct optical lithography of inorganic nanoparticles (DOLFIN) method is particularly promising, offering fast and customizable nanocrystal film patterns. ${ }^{\left[{ }^{[8]}\right.}$ DOLFIN exploits a photodecomposition reaction of surface ligands, exposed to UV light through the mask. This rigidifies the exposed parts of the nanoparticle film, while the unexposed regions retain their initial solubility and can be removed by polar developer solution. Using DOLFIN, positive and negative patterning is possible as well as multilayer deposition sequence. ${ }^{[98]}$

\section{Post-deposition Treatment}

Fabricated $\mathrm{PbS}$ nanocrystal solids can be treated thermally or chemically. Annealing, doping, and protection of $\mathrm{PbS}$ nanocrystal layers are common post-deposition treatment approaches, which aims for an improvement of film stability and overall device performance through the modification of thin film composition and also the surface of individual nanocrystals.

In a layer-by-layer solid-state ligand exchange procedure some of the halide ligands might be washed away from the nanocrystal surfaces after the exchange. Ding et al. ${ }^{[100]}$ developed a post-deposition treatment to re-add the lost halides by soaking the deposited $\mathrm{PbS}$ film in methylammonium salt (MAX, $\mathrm{X}=\mathrm{I}^{-}$, $\mathrm{Br}^{-}$, or $\mathrm{Cl}^{-}$).

\section{(A) Dip Coating}

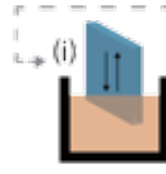

(B) Spin Coating

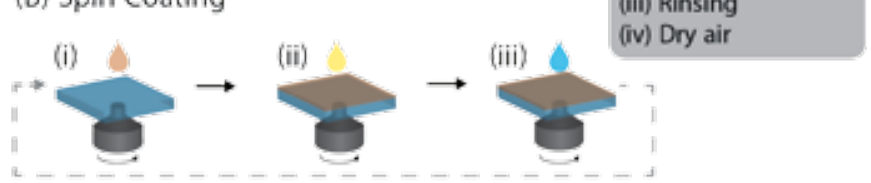

(C) Spray Coating

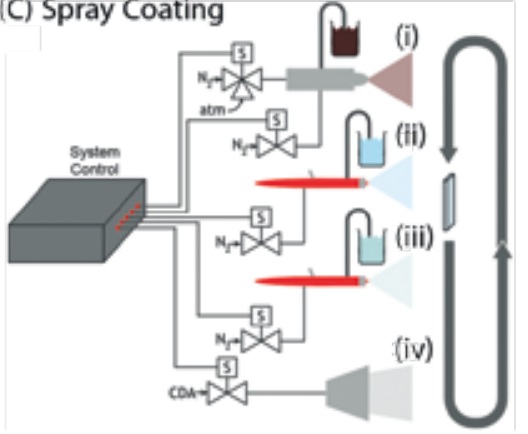

Fig. 6. Schematic depiction of (A) dip coating, (B) spin coating and $(C)$ spray coating deposition techniques for $\mathrm{PbS}$ nanocrystal inks, designed as a multilayer deposition sequence. ${ }^{[91]}$ 
Mild annealing of $\mathrm{PbS}$ nanocrystal thin films (typically, below $100{ }^{\circ} \mathrm{C}$ ) is carried out to remove volatile organics, such as solvent remains and excessive ligand molecules. This leads to more dense nanocrystal solids, while preventing the coalescence of individual nanocrystals and thus retaining the film ordering and quantum size effects. Moreover, annealing may also notably improve the overall device performance. Cao et al..$^{[101]}$ demonstrated that ligand surface coverage can be increased after short annealing at $80^{\circ} \mathrm{C}$ in an $\mathrm{N}_{2}$ atmosphere. Unbounded thiols are activated at this temperature and can replace the hydroxyl ions at the $\mathrm{PbS}$ nanocrystal surface. This leads to improved performance as well as photostability of $\mathrm{PbS}$ solar cells. Gao et al. ${ }^{[102]}$ showed that annealing at higher temperatures (100-120 $\left.{ }^{\circ} \mathrm{C}\right)$ may enable a rearrangement of $\mathrm{PbS}$ nanocrystals within the film. Authors reported up to $50 \%$ efficiency boost for $\mathrm{PbS}$ solar cells, associated with the growth of ordered domains in the nanocrystal solid during annealing. More ordered films showed better electronic coupling and consequently improved carrier transport and photocurrent. ${ }^{[102]}$ Annealing in air improves some aspects of device efficiency (built-in voltage, open-circuit voltage) and overall device performance due to the formation of an oxide monolayer on $\mathrm{PbS}$ surface (i.e. $\mathrm{PbO}$ and $\mathrm{PbSO}_{3}$ species). ${ }^{[89,93,103]}$ Higher annealing temperatures of $\mathrm{PbS}$ nanocrystal solids result in fusion of nanocrystals. ${ }^{[102]} \mathrm{Kim}$ et $a l .{ }^{[104]}$ developed a two-step annealing process. In the first step the thin-films are annealed in air to form sulfonate on the [111] $\mathrm{Pb}$-rich surfaces, while in the second step they are annealed in a nitrogen atmosphere, this removes the insulting oxygen from the [100] surface of the NCs. The treated thin-films show an improved hole transport and therefore improved efficiency in a solar cell.

NC thin films manufactured in high humidity conditions show less oxygen functionalization on the NCs surface and therefore p-doping. ${ }^{[66]}$ This can be reversed by one day of dry air exposure ${ }^{[66]}$ or a short exposure to oxygen plasma. ${ }^{[105]}$

Doping $\mathrm{PbS}$ thin films provides opportunities to design electronic structure and transport properties of nanocrystal solids. Electron affinity of surface-covering ligands defines the position of Fermi level in the band gap and the type of doping (i.e. $\mathrm{n}$ or p-doped films). ${ }^{[53,106]}$ Ligand engineering is a flexible way to design gradient doping throughout the $\mathrm{PbS}$ nanocrystal solid and consequently an optimal band gap alignment for quantum dot photovoltaics. ${ }^{[56]}$ Post-deposition doping of nanocrystal solids can also be tuned by achieving an off-stoichiometric composition of nanocrystals (i.e. Pb-rich or Se-rich $\mathrm{PbSe}$ nanocrystals) ${ }^{[107]}$ and by remote doping with cations (e.g. $\mathrm{Ag}^{+}$-doped $\mathrm{HgTe}$ nanocrystals) ${ }^{[108]}$ or with molecular complexes (e.g. cobaltocenetreated $\mathrm{PbS}$ nanocrystals). ${ }^{[109]}$

Protection of $\mathrm{PbS}$ nanocrystal solids is a way to improve longevity of thin film devices. Deposition of such capping layers can be designed to also encapsulate individual nanocrystals and even fill interparticle voids with chemically inert and stable material. Moroz et al. ${ }^{[110]}$ developed an encapsulation method of $\mathrm{PbS}$ solids, forming efficient and stable infrared emitters. The authors used a layer-by-layer deposition of $\mathrm{Cd}$ and $\mathrm{S}$ ions, reminiscent of a chemical bath deposition (CBD) method. Infilling the nanocrystal solids is also possible using the atomic layer deposition (ALD) technique, which was demonstrated e.g. for nanocrystal-based $\mathrm{PbS}$ photovoltaics ${ }^{[62]}$ and $\mathrm{PbSe}$ field-effect transistors. ${ }^{[63]}$ ALD-infilling of nanocrystal solids leads to improved device characteristics and long-lasting operation in air. ${ }^{[62,63]}$

The nanocrystals can also be used in combination with other emerging materials. For example, in a hybrid approach, the nanocrystal hole transport layer is replaced with an organic material for higher performance and simpler fabrication. ${ }^{[11,112]}$ Or using nanocrystals in a tandem solar cell together with an perovskite layer allows to exploit the tunability of the nanocrystals combined with the good visible light absorption of the perovskite layer, leading to high-performance solar cells. ${ }^{[113]}$

\section{Step 4: Characterization of Thin Films}

Characterizing a thin film is crucial to enable sample-to-sample reproducibility and to understand the properties of nanocrystal solids, where even thin films made from the same nanocrystals may have different electronic and optical properties depending on the deposition methodology and applied post-deposition treatments.

\section{Film Thickness and Surface Roughness}

A quick glance at a $\mathrm{PbS}$ film can give a good indication about thickness and film quality. The thickness of the $\mathrm{PbS}$ thin film can be inferred from its color and the physical smoothness of the nanocrystal thin film correlates with its shininess (i.e. glossy film surface indicates a good film quality). ${ }^{[55,71]}$

Atomic force microscopy (AFM) is commonly used to measure the roughness of nanocrystal thin film (Fig. 7A), ${ }^{[14]}$ as well as the thickness of the nanocrystal thin film for thinner thin films (up to 300-500 nm) that can be scratched. Similarly, a profilometer can be employed to measure thickness and roughness of micrometer-thick nanocrystal thin films. ${ }^{[115]}$ Even thicker nanocrystal layers can also be characterized by scanning electron microcopy (SEM). ${ }^{[85]}$ The sample can be cleaved and viewed in cross-sectional (XS) geometry (Fig. 7B). ${ }^{[116]}$ XSSEM gives insights about the structure of thin films, such as void distribution, nanocrystal arrangement, superlattice domain size, etc.

\section{Composition of the Film}

Quantifying the composition of the $\mathrm{PbS}$ nanocrystal thin film (both the atomic percent of inorganic and organic components) is important. As discussed in section 2, nanocrystal stoichiometry impacts the electronic structures and number of free charges. ${ }^{[47]}$ The type and number of ligands will influence how nanocrystals pack, both in terms of packing (geometry) and in terms of nanocrystal spacing[50,51] as well as the electronic properties. [117,118]

FTIR is used to analyze the organic content of nanocrystals thin films. The amount of initial ligand and solvent, success (i.e. completeness) of the ligand-exchange procedure, $[28,55,119-121]$ ligand ratio, identity and density of organic ligands ${ }^{[29]}$ are among typical tasks for FTIR spectroscopy. A total amount of organic molecules can also be determined from thermogravimetric analysis (TGA). ${ }^{[93]}$

The inorganic part of the film $(\mathrm{Pb}, \mathrm{S}$ and inorganic ligand shell) can be examined by X-ray photoelectron spectroscopy (XPS), ${ }^{1120,122]}$ ICP-AES[6,123] or energy-dispersive X-ray spectroscopy (EDX). ${ }^{[124]}$ XPS comes with the advantage of being able to distinguish between different oxidation states and chemical environments of elements. While ICP-AES is more sensitive and more precise than EDX, ICP-AES sample preparation is more involved (the thin film has to dissolved in a strong mineral acid like $\mathrm{HNO}_{3}$ or $\mathrm{HCl}$ ).

\section{Packing and Ordering of Nanocrystals within Thin Films}

To determine interparticle spacing and ordering, X-ray scattering methods such grazing-incidence small-angle X-ray scattering (GISAXS), grazing-transmission small-angle X-ray scattering (GTSAXS), and wide-angle X-ray scattering (WAXS) have been used (Fig. 8A). ${ }^{[50]}$

Highly monodisperse $\mathrm{PbS}$ nanocrystals can order into simple superlattices with high packing factors (e.g. face-centered cubic (fcc) lattice). The PbS thin film ordering can be tuned by the density of surface ligands. ${ }^{[125]}$ While nanocrystals with dense surface ligand shells self-assemble into face-centered cubic (fcc), less dense ligand coverage results in body-centered cubic (bcc) superlattice. The ligands used in the ligand-exchange process directly influence the interparticle distance (i.e. longer ligands lead to larger interparticle distances, Fig. 8B). At the 
same time, the superlattice order is similar prior to and after the ligand exchange (Fig. 8A). As shown for oleate-capped $\mathrm{PbS}$ nanocrystals, the thin film ordering can be improved by drying it in or exposing the dried films to the solvent saturated vapor. ${ }^{[126]}$

The deposition method and conditions can influence the ordering of $\mathrm{PbS}$ nanocrystals in a thin film. For example, a onestep spin coating of a thick film of nanocrystals (as opposed to multistep deposition) is beneficial for long-range ordering, while also minimizing the density of voids within the film (Fig. 8A). ${ }^{[50]}$ The disadvantage of such one-step deposition is the appearance of cracks in thick films due to volume shrinkage caused by the ligand exchange. ${ }^{[50]}$

\section{Optical and Electronic Properties of PbS Thin Films}

Absorption of a nanocrystal thin film is a key parameter for its use in a solar cell. One of the challenges in thin film is a quantitative measurement of absorptance since most $\mathrm{PbS}$ layers are quite thin, requiring not only transmission but also reflectance measurements. An alternative is to use PDS (photothermal deflection spectroscopy) instead, ${ }^{[127]}$ where a monochromatic pump beam is absorbed by the sample and thus creating a temperature and refractive index gradient in the material adjacent to the test sample. The deflection of a probe laser measures this gradient and is directly proportional to absorbed power.

In general, the optical properties of thin films yield important insights about the quality of the film and the absorptivity, and photoluminescence, particularly and, particularly when compared to the optical properties of the nanocrystals in solution. ${ }^{[120,128,129]}$ For example, in solution, nanocrystals are isolated from each other; however, in $\mathrm{PbS}$ quantum dot thin films the interparticle distance is on the order of $1 \mathrm{~nm}$ (Fig. 8B), leading to effects such as Förster resonance energy transfer (FRET) and changes to the dielectric function. ${ }^{[128,130,131]}$ These in turn can have an important impact on recombination dynamics and the charging energy of the nanocrystals. Recombination dynamics in particular, benefit from time-dependent measurements such as photoluminescence decay, luminesce lifetimes can be extracted. This information helps to deduce the mechanism and dynamics of photoexcited charge carries, including trapping and recombination processes. ${ }^{[132]}$ Photoluminescence decay is often used to compare $\mathrm{PbS}$ thin films, prepared from various syntheses and deposition protocols. For example, Wang et al. reported the suppression of traps states within $\mathrm{PbS}$ thin film, when $\mathrm{PbS}$ nanocrystals are prepared from $\mathrm{Pb}$ acetate precursor (instead of $\mathrm{PbO}$ traditional synthesis). [133] Transients absorption (TA) spectroscopy allows the measurement of photogenerated excited state absorption and their lifetimes, by measuring the absorbance of a sample after it has been excited by a short flash of light. For example, Leventis et al. used this technique to study the charge separation yield of $\mathrm{PbS} / \mathrm{SnO}_{2}$ compared to $\mathrm{PbS} / \mathrm{TiO}_{2}{ }^{[134]}$

Electrical properties of $\mathrm{PbS}$ thin films are also relevant for optoelectronic devices. While the nanocrystal-based thin films can be measured in many of the same ways as bulk semiconductors
(A)

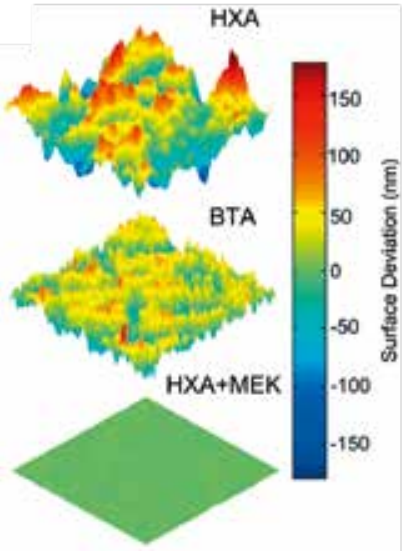

(B)

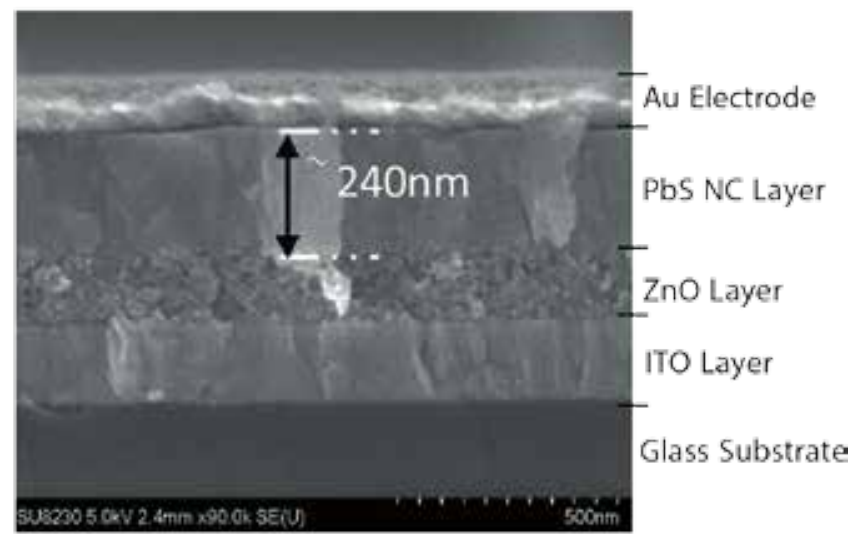

Fig. 7. (A) AFM topography maps of $\mathrm{PbS}$ thin films, exhibiting different surface roughness as a function of ink solvent (HXA is hexylamine; BTA is $n$-butylamine; MEK is methyl ethyl ketone). ${ }^{114]}$ (B) SEM cross section of a cleaved $\mathrm{PbS}$ heterojunction solar cell, showing a thickness and morphology of each layer. ${ }^{[85]}$
(A)

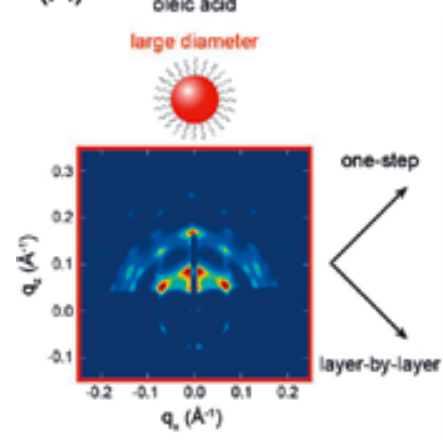

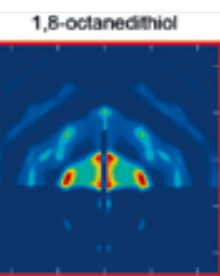

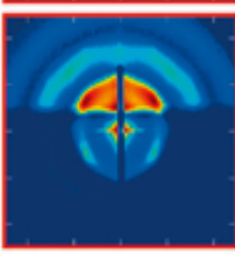

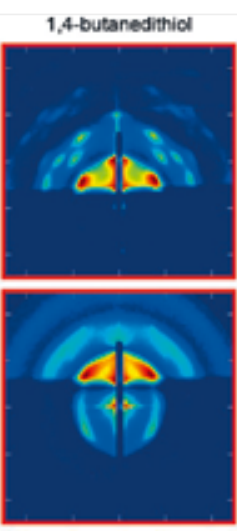

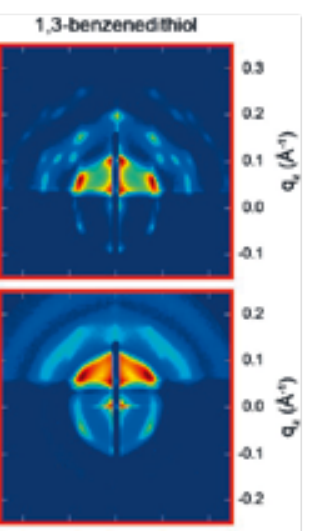

(B)
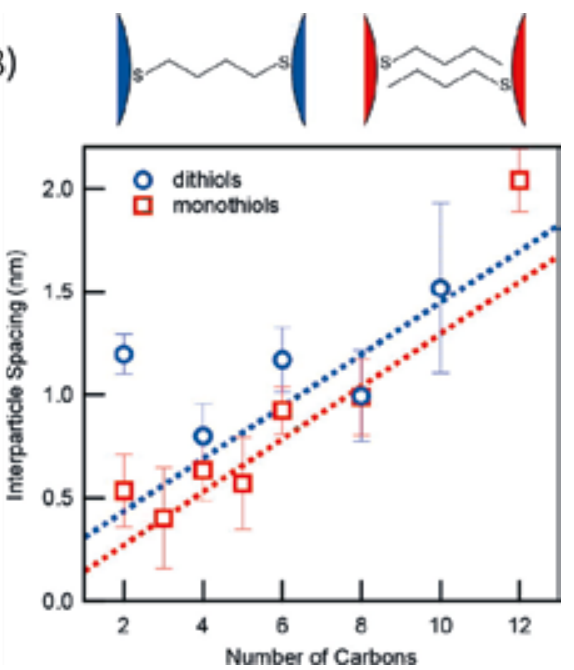

Fig. 8. (A) GISAXS maps of PbS nanocrystal thin films before and after solid-state ligand exchange. One-step spin-coating approach facilitates better ordering than layer-by-layer deposition. ${ }^{[50]}(\mathrm{B})$ Measured interparticle-distance as a function of the number of carbon atoms in mono- and di-thiol ligands. The dashed lines indicate calculated distances. ${ }^{[50]}$ 
(e.g. capacitance-voltage, ${ }^{[135]}$ time-of-flight ${ }^{[41]}$ or ultraviolet photoelectron spectroscopy[53]) and nanocrystal-based devices can be modeled using standard drift-diffusion models, ${ }^{[136]}$ the properties differ due to the nature of the individual quantum dot building blocks that facilitates charge localization (e.g. what creates electronics trap states, ${ }^{[137]}$ how free carriers are generated or governs charge carrier mobility and the temperature dependence). This means that analysis of the electrical properties of nanocrystal crystal thin films requires careful modeling[47] and often a multi-pronged approach. ${ }^{[135,138]}$ For example, Volk et al. ${ }^{[139]}$ used a combination of measurements to show midgap electronic states of nanocrystals solids stemming from nanocrystal dimerization ${ }^{[140]}$ and charging of doped nanocrystals. ${ }^{[47]}$ In particular, the time aspects associated with charge localization in the film must be kept in mind when designing the measurement protocols.

\section{Outlook: Realizing Nanocrystal Devices}

While $\mathrm{PbS}$ nanocrystal thin films have been used in many devices (see Fig. 9), ${ }^{[141]}$ including photodetectors, ${ }^{[142]}$ infrared LEDs, ${ }^{[143]}$ mid- and long-wave infrared detectors, ${ }^{[144]}$ luminescent solar concentrators, ${ }^{[145]}$ thermoelectrics ${ }^{[146]}$ and field-effect transistors. ${ }^{[124]}$ Due to carrier multiplication in $\mathrm{PbS}$ thin films (i.e. two or more carriers are created per photon that is larger than twice the band gap) $)^{[147]} \mathrm{NC}$ solar cells have the potential to overcome the Shockley-Queisser solar cell limit. PbS-based solar cells can also be combined with silicon solar cells to improve performance due to the additional absorption in the infrared range. ${ }^{[114]}$

First, we take the example of their use in solar cells. An overview of the progress in $\mathrm{PbS}$ nanocrystal solar cell efficiency over the past 10 years is summarized in Table 2. Each performance gain can be linked back to improvements in synthesis, thin-film fabrication procedure, and/or improved device architecture, all of which are linked to manipulating the nanocrystal surface chemistry or leveraging it effectively in the device. We show this with three examples:

1) In 2011 Tang et al. ${ }^{[65]}$ introduced cadmium ions to the $\mathrm{PbS}$ synthesis (in the form of $\mathrm{CdCl}_{2}$ ) immediately after nanocrystals formed. Additionally, authors changed the crosslinking ligands from the organic 1,2-ethanedithiol (EDT) to an inorganic halide $\left(\mathrm{Br}^{-}\right)$. This post-synthetic surface engineering leads to high carrier mobility $\left(4 \times 10^{-2} \mathrm{~cm}^{2} \mathrm{~V}^{-1} \mathrm{~s}^{-1}\right)$ and improved device power conversion efficiency.

2) In 2014, Chuang et al. ${ }^{[56]}$ showed different ligands can be

Device performance depends on individual nanocrytal surface.

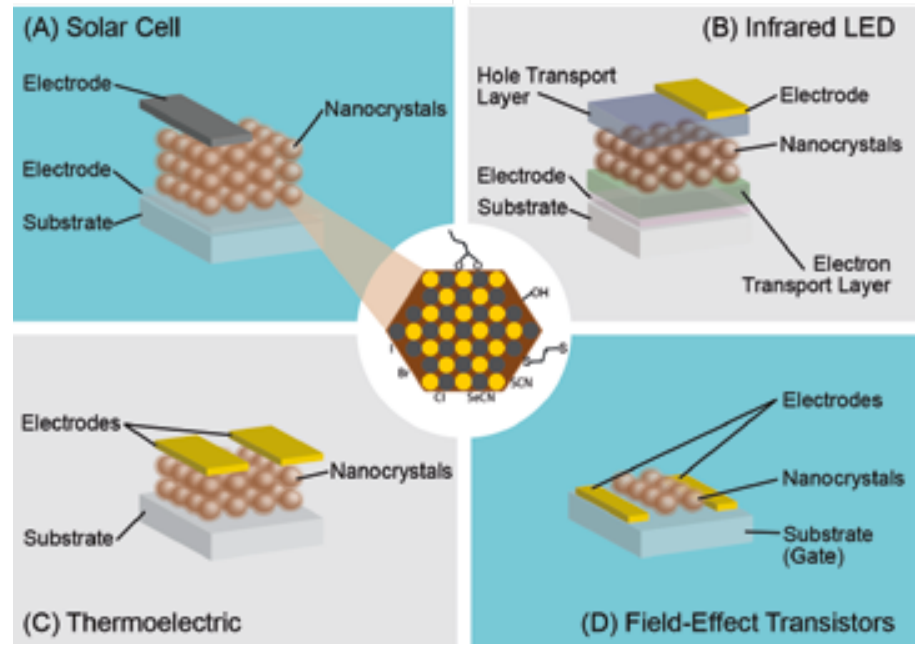

Fig. 9. Schematic depiction of PbS nanocrystal devices: (A) solar cell, (B) infrared LED, (C) thermoelectric generator and (D) field-effect transistor. used to shift $\mathrm{PbS}$ energy levels, allowing engineering of band alignment. In this case a thick PbS layer $(180 \mathrm{~nm})$ cross linked with iodine (I) is the main absorber layer. On top of this layer, a thin $\mathrm{PbS}$ layer $(46 \mathrm{~nm})$ cross linked with 1,2-ethanedithiol (EDT) is deposited. Due to a small shift in energy levels the $\mathrm{PbS}$-EDT layer is acting as an electron-blocking and holeextracting layer and improved device efficiency.

3) In 2016 Liu et al.[7] developed a solution ligand-exchange protocol as opposed to previously used solid-state ligandexchange for $\mathrm{PbS}$ thin films. This results in higher packing density and sharper band tails, leading to improved charger transport and carrier injection into the electrode. In turn, thicker absorber layers and therefore improved power conversion efficiency have been achieved.

Another example is the use of $\mathrm{PbS}$ nanocrystals in infraredemitting LEDs. To achieve high photoluminescent quantum yields, $\mathrm{PbS}$ nanocrystals are typically covered with a thin CdS shell[153,154] or the nanocrystal surface is site-selectively passivated using trioctylphosphine. ${ }^{[155]}$ Similarly to $\mathrm{PbS}$ solar cells, for the $\mathrm{PbS}$ nanocrystal LEDs, we see the importance and impact of surfaces and the immediate environment of the nanocrystals. For example, recent work has shown how the NC surface impacts electronphonon coupling strength and linewidth and recombination dynamics. ${ }^{[10,156]}$

In summary, these examples from the $\mathrm{PbS}$ nanocrystal device space highlight the importance of control and characterization of nanocrystal surfaces. While the trend has been to think of nanocrystals as small particles of bulk, their large surface to volume ratios make the unique surface chemistry perhaps equally as important as the bulk. Methods for control of nanocrystal surfaces during synthesis, post-synthetic treatments, and thin film deposition as well as approaches to characterize and simulate surfaces will be of upmost importance in the coming years to enable more widespread commercialization of nanocrystals devices. While the surfaces of nanocrystals are buried in the final thin film, they are critical. Future research must concentrate on achieving understanding and control of nanocrystal surfaces at all stages from synthesis to thin film.

The progress over the last 20 years in $\mathrm{PbS}$ nanocrystal research has been fueled by improvements on all aspects. Continuous improvement to synthetic recipes has resulted in control over nanocrystal size, shape, surface, and stoichiometry. Thanks to better understanding of the nanocrystal surface chemistry, improved deposition processes were established and thin films with tunable properties are enabled. The work has also highlighted that $\mathrm{PbS}$ nanocrystal thin films comprise only one layer in a device. The device architecture as well as all the other materials and their deposition methods have to be carefully selected, all while considering various morphological and electronic properties, such as band alignment between layers, composition, thickness, and surface area, charge carrier concentration, etc.

These improvements have partially been fueled by better understanding of the underlying processes, due to better characterization. Advancement in characterization techniques such as using multimodal techniques, that offer spatio-temporally resolved information on carrier transport (e.g. transient PL microscopy or TA microscopy ${ }^{[157]}$ ), can improve the understanding even further. Novel characterization methods, not just for the nanocrystals but also the full devices, enable in situ or in operando measurements on a real device (e.g. in situ GISAXS, ${ }^{[158]}$ in situ FTIR, in situ TA, ${ }^{[159]}$ in situ PL, ${ }^{[160]}$ or Time-Resolved X-Ray Photoemission Measurements (TRXPS $)^{[161]}$, which allows a better understanding of the processes taking place in assembled devices.

While most of the research in nanocrystal-based solar cells has been carried out using $\mathrm{PbS}$, it is not likely to be the most commercially relevant system. ${ }^{[162,163]}$ Nonetheless, the knowledge 
Table 2. Record-setting PbS solar cells synthesis and fabrication modification.

\begin{tabular}{|c|c|c|c|c|}
\hline Record [\%] & Date & Synthesis Modification & Fabrication Modification & Ref. \\
\hline 2.94 & 2010, Aug. & $\begin{array}{l}\text { Classical: } \\
\text { Hot injection synthesis }\end{array}$ & $\begin{array}{l}\text { First record devices } \\
\text { Dip coating } \\
\mathrm{ZnO} \text { heterojunction } \\
\mathrm{PbS} \text { with EDT-ligand }\end{array}$ & [148] \\
\hline 4.40 & 2011, June & Classical & Adding MoOx layer & [149] \\
\hline 5.10 & 2011, Sept. & $\begin{array}{l}\text { Atomic ligand passivation: } \\
\mathrm{CdCl}_{2}-\mathrm{TDPA}-\mathrm{OLA} \text { treatment }\end{array}$ & $\begin{array}{l}\text { Spin coating } \\
\mathrm{TiO}_{2} \text { heterojunction } \\
\text { PBS with Br-ligand }\end{array}$ & {$[65]$} \\
\hline 7.0 & 2012, July & Halide treatment: $\mathrm{Pb}: \mathrm{Cd}$ added during cooldown & PBS with MPA-ligand & [79] \\
\hline 8.55 & 2014, May & Classical & $\begin{array}{l}\text { Band alignment engineering } \\
\mathrm{ZnO} \text { heterojunction }\end{array}$ & [56] \\
\hline 9.20 & 2014, Dec. & Classical & $\begin{array}{l}\text { Dip coating } \\
\text { Pyramid patterned } \mathrm{TiO}_{2}\end{array}$ & [150] \\
\hline 9.90 & 2015, Nov. & Post-synthesis $I_{2}$ treatment & - & {$[151]$} \\
\hline 10.60 & 2016, June & Post-synthesis methylammonium iodide treatment & - & [85] \\
\hline 11.28 & 2016, Nov. & $\begin{array}{l}\text { Solution ligand exchange with } \mathrm{PbI}_{2} \\
\text { and } \mathrm{NH}_{4} \mathrm{Ac}\end{array}$ & $\mathrm{PbS}$ ink spin coating & [7] \\
\hline 12.01 & 2018, April & Solution ligand exchange with $\mathrm{PbI}_{2}, \mathrm{PbBr}_{2}$ and $\mathrm{NH}_{4} \mathrm{Ac}$ & $\begin{array}{l}\text { Addition of hybrid inorganic- } \\
\text { amine coordinating complex to set } \\
\text { internanoparticle spacing }\end{array}$ & [152] \\
\hline 12.47 & 2020, Jan & $\begin{array}{l}\text { Solution ligand exchange creating } n \text {-type and } p \text {-type } \\
\text { nanocrystals }\end{array}$ & $\begin{array}{l}\text { Spin coating of a mixture of } n \text {-type } \\
\text { and } p \text {-type nanocrystals }\end{array}$ & [86] \\
\hline
\end{tabular}

gained from the development and characterization of $\mathrm{PbS}$ nanocrystals and devices will facilitate their use for example in photodiode applications ${ }^{[164,165]}$ or can be applied to the development of other nanocrystal chemistries for solar cells, such as leadhalide perovskites as well as non-toxic, lead-free nanocrystals such as $\mathrm{AgBiS}_{2},{ }^{[166]} \mathrm{Cu}_{2} \mathrm{~S},{ }^{[167]}$ or $\mathrm{Cu}_{3} \mathrm{BiS}_{3}$ nanocrystals. [168]

\section{Acknowledgements}

This work has been financially supported by the Swiss National Science Foundation via research projects through the Quantum Sciences and Technology NCCR and the ETH Research Grant (No. 42-12-2). M.Y. acknowledges funding from the European Research Council (ERC) under the European Union's Horizon 2020 research and innovation programme (grant agreement No. 852751).

Received: February 7, 2021

[1] D. V. Talapin, J.-S. Lee, M. V. Kovalenko, E. V. Shevchenko, Chem. Rev 2010, 110, 389, https://doi.org/10.1021/cr900137k.

[2] P. Reiss, M. Carrière, C. Lincheneau, L. Vaure, S. Tamang, Chem. Rev. 2016, 116, 10731, https://doi.org/10.1021/acs.chemrev.6b00116.

[3] A. L. Rogach, A. Eychmüller, S. G. Hickey, S. V. Kershaw, Small 2007, 3, 536, https://doi.org/10.1002/smll.200600625.

[4] S. V. Kershaw, A. S. Susha, A. L. Rogach, Chem. Soc. Rev. 2013, 42, 3033 , https://doi.org/10.1039/c2cs35331h.

[5] A. Parveen, S. Agrawal, A. Azam, Opt. Mater. (Amst). 2018, 76, 21, https://doi.org/10.1016/j.optmat.2017.12.015.

[6] L. Cademartiri, E. Montanari, G. Calestani, A. Migliori, A. Guagliardi, G. A. Ozin, J. Am. Chem. Soc. 2006, 128, 10337, https://doi.org/10.1021/JA063166U.

[7] M. Liu, O. Voznyy, R. Sabatini, F. P. García de Arquer, R. Munir, A. H. Balawi, X. Lan, F. Fan, G. Walters, A. R. Kirmani, S. Hoogland, F. Laquai, A. Amassian, E. H. Sargent, Nat. Mater. 2017, 16, 258, https://doi.org/10.1038/nmat4800.

[8] T. Rauch, M. Böberl, S. F. Tedde, J. Fürst, M. V. Kovalenko, G. Hesser, U. Lemmer, W. Heiss, O. Hayden, Nat. Photonics 2009, 3, 332, https://doi.org/10.1038/nphoton.2009.72.

[9] K. Szendrei, F. Cordella, M. V. Kovalenko, M. Böberl, G. Hesser, M. Yarema, D. Jarzab, O. V. Mikhnenko, A. Gocalinska, M. Saba, F. Quochi, A. Mura, G. Bongiovanni, P. W. M. Blom, W. Heiss, M. A. Loi, Adv. Mater. 2009, 21, 683, https://doi.org/10.1002/adma.200801752.
[10] N. Yazdani, D. Bozyigit, K. Vuttivorakulchai, M. Luisier, I. Infante, V. Wood, Nano Lett. 2018, 18, 2233, https://doi.org/10.1021/acs.nanolett.7b04729.

[11] D. Zherebetskyy, M. Scheele, Y. Zhang, N. Bronstein, C. Thompson, D. Britt, M. Salmeron, P. Alivisatos, L.-W. Wang, Science 2014, 344, 1380, https://doi.org/10.1126/science.1252727.

[12] S. Z. Bisri, E. Degoli, N. Spallanzani, G. Krishnan, B. J. Kooi, C. Ghica, M. Yarema, W. Heiss, O. Pulci, S. Ossicini, M. A. Loi, Adv. Mater. 2014, 26 , 5639, https://doi.org/10.1002/adma.201400660.

[13] M. C. Weidman, M. E. Beck, R. S. Hoffman, F. Prins, W. A. Tisdale, ACS Nano 2014, 8, 6363, https://doi.org/10.1021/nn5018654.

[14] A. Shrestha, N. A. Spooner, S. Z. Qiao, S. Dai, Phys. Chem. Chem. Phys. 2016, 18, 14055, https://doi.org/10.1039/C6CP02119K.

[15] J. W. Lee, D. Y. Kim, S. Baek, H. Yu, F. So, Small 2016, 12, 1328, https://doi.org/10.1002/smll.201503244.

[16] N. Zhao, L. Qi, Adv. Mater. 2006, 18, 359, https://doi.org/10.1002/adma.200501756.

[17] H. Li, D. Chen, L. Li, F. Tang, L. Zhang, J. Ren, CrystEngComm 2010, 12, 1127, https://doi.org/10.1039/B917833C.

[18] M. A. Hines, G. D. Scholes, Adv. Mater. 2003, 15, 1844 https://doi.org/10.1002/adma.200305395.

[19] L. Cademartiri, J. Bertolotti, R. Sapienza, D. S. Wiersma, G. von Freymann, G. A. Ozin, J. Phys. Chem. B 2006, 110, 671, https://doi.org/10.1021/jp0563585.

[20] J. Zhang, J. Gao, E. M. Miller, J. M. Luther, M. C. Beard, ACS Nano 2014 , 8, 614, https://doi.org/10.1021/nn405236k.

[21] A. H. Khan, R. Brescia, A. Polovitsyn, I. Angeloni, B. Martín-García, I. Moreels, Chem. Mater. 2017, 29, 2883, https://doi.org/10.1021/acs.chemmater.6b05111.

[22] C. Schliehe, B. H. Juarez, M. Pelletier, S. Jander, D. Greshnykh, M. Nagel, A. Meyer, S. Foerster, A. Kornowski, C. Klinke, H. Weller, Science 2010, 329,550 , https://doi.org/10.1126/science. 1188035 .

[23] M. P. Hendricks, M. P. Campos, G. T. Cleveland, I. Jen-La Plante, J. S. Owen, Science 2015, 348, 1226, https://doi.org/10.1126/science.aaa2951.

[24] NREL chart. https://www.nrel.gov/pv/cell-efficiency.html, 2020.

[25] J. Choi, Y. Kim, J. W. Jo, J. Kim, B. Sun, G. Walters, F. P. García de Arquer, R. Quintero-Bermudez, Y. Li, C. S. Tan, L. N. Quan, A. P. T. Kam, S. Hoogland, Z. Lu, O. Voznyy, E. H. Sargent, Adv. Mater. 2017, 29, 1702350, https://doi.org/10.1002/adma.201702350.

[26] K. A. Abel, J. Shan, J.-C. Boyer, F. Harris, F. C. J. M. van Veggel, Chem. Mater. 2008, 20, 3794, https://doi.org/10.1021/cm702564a.

[27] P. B. Green, P. Narayanan, Z. Li, P. Sohn, C. J. Imperiale, M. W.B. Wilson, Chem. Mater. 2020, 32, 4083, https://doi.org/10.1021/acs.chemmater.0c00984. 
[28] J. Tang, L. Brzozowski, D. A. R. Barkhouse, X. Wang, R. Debnath, R. Wolowiec, E. Palmiano, L. Levina, A. G. Pattantyus-Abraham, D. Jamakosmanovic, E. H. Sargent, ACS Nano 2010, 4, 869, https://doi.org/10.1021/nn901564q.

[29] M. Yarema, O. Yarema, W. M. M. Lin, S. Volk, N. Yazdani, D. Bozyigit, V. Wood, Chem. Mater. 2017, 29, 796, https://doi.org/10.1021/acs.chemmater.6b04789.

[30] D. Bozyigit, N. Yazdani, M. Yarema, O. Yarema, W. M. M. Lin, S. Volk, K. Vuttivorakulchai, M. Luisier, F. Juranyi, V. Wood, Nature 2016, 531, 618, https://doi.org/10.1038/nature16977.

[31] S. Mourdikoudis, L. M. Liz-Marzán, Chem. Mater. 2013, 25, 1465 , https://doi.org/10.1021/cm4000476.

[32] I. Moreels, Y. Justo, B. De Geyter, K. Haustraete, J. C. Martins, Z. Hens, ACS Nano 2011, 5, 2004, https://doi.org/10.1021/nn103050w.

[33] S. W. Winslow, Y. Liu, J. W. Swan, W. A. Tisdale, ACS Mater. Lett. 2019, 1 , 209, https://doi.org/10.1021/acsmaterialslett.9b00200.

[34] J. H. Warner, H. Cao, Nanotechnology 2008, 19, 305605, https://doi.org/10.1088/0957-4484/19/30/305605.

[35] Y. Jiang, Y. Wu, B. Xie, S. Yuan, X. Liu, Y. Qian, J. Cryst. Growth 2001, 231, 248, https://doi.org/10.1016/S0022-0248(01)01510-X.

[36] Y. Shen, M. Y. Gee, A. B. Greytak, Chem. Commun. 2017, 53, 827, https://doi.org/10.1039/C6CC07998A

[37] A. Hassinen, I. Moreels, K. De Nolf, P. F. Smet, J. C. Martins, Z. Hens, J. Am. Chem. Soc. 2012, 134, 20705, https://doi.org/10.1021/ja308861d.

[38] A. R. Kirmani, G. H. Carey, M. Abdelsamie, B. Yan, D. Cha, L. R. Rollny, X. Cui, E. H. Sargent, A. Amassian, Adv. Mater. 2014, 26, 4717, https://doi.org/10.1002/adma.201400577.

[39] N. C. Anderson, M. P. Hendricks, J. J. Choi, J. S. Owen, J. Am. Chem. Soc. 2013, 135, 18536, https://doi.org/10.1021/ja4086758.

[40] A. Gocalinska, M. Saba, F. Quochi, M. Marceddu, K. Szendrei, J. Gao, M. A. Loi, M. Yarema, R. Seyrkammer, W. Heiss, A. Mura, G. Bongiovanni, $J$. Phys. Chem. Lett. 2010, 1, 1149, https://doi.org/10.1021/jz100116t.

[41] N. Yazdani, D. Bozyigit, O. Yarema, M. Yarema, V. Wood, J. Phys. Chem. Lett. 2014, 5, 3522, https://doi.org/10.1021/jz5015086.

[42] Z. Ning, O. Voznyy, J. Pan, S. Hoogland, V. Adinolfi, J. Xu, M. Li, A. R. Kirmani, J.-P. Sun, J. Minor, K. W. Kemp, H. Dong, L. Rollny, A. Labelle, G. Carey, B. Sutherland, I. Hill, A. Amassian, H. Liu, J. Tang, O. M. Bakr, E. H. Sargent, Nat. Mater. 2014, 13, 822, https://doi.org/10.1038/nmat4007.

[43] T. Li, A. J. Senesi, B. Lee, Chem. Rev. 2016, 116, 11128, https://doi.org/10.1021/acs.chemrev.5b00690

[44] R. T. Lechner, G. Fritz-popovski, M. Yarema, W. Heiss, A. Hoell, T. U. Schu, D. Primetzhofer, M. Eibelhuber, O. Paris, Chem. Mater. 2014, 26, 5914, https://doi.org/10.1021/cm502521q.

[45] I. Moreels, K. Lambert, D. Smeets, D. De Muynck, T. Nollet, J. C. Martins, F. Vanhaecke, A. Vantomme, C. Delerue, G. Allan, Z. Hens, ACS Nano 2009, 3, 3023, https://doi.org/10.1021/nn900863a.

[46] I. Kang, F. W. Wise, J. Opt. Soc. Am. B 1997, 14, 1632, https://doi.org/10.1364/JOSAB.14.001632.

[47] N. Yazdani, S. Andermatt, M. Yarema, V. Farto, M. H. Bani-Hashemian, S. Volk, W. M. M. Lin, O. Yarema, M. Luisier, V. Wood, Nat. Commun. 2020 , 11, 2852, https://doi.org/10.1038/s41467-020-16560-7.

[48] H. Choi, J.-H. Ko, Y.-H. Kim, S. Jeong, J. Am. Chem. Soc. 2013, 135, 5278, https://doi.org/10.1021/ja400948t.

[49] A. Stavrinadis, A. K. Rath, F. P. G. de Arquer, S. L. Diedenhofen, C. Magén, L. Martinez, D. So, G. Konstantatos, Nat. Commun. 2013, 4, 2981, https://doi.org/10.1038/ncomms3981.

[50] M. C. Weidman, K. G. Yager, W. A. Tisdale, Chem. Mater. 2015, 27, 474, https://doi.org/10.1021/cm503626s.

[51] M. C. Weidman, Q. Nguyen, D.-M. Smilgies, W. A. Tisdale, Chem. Mater 2018, 30, 807, https://doi.org/10.1021/acs.chemmater.7b04322.

[52] Y. Liu, M. Gibbs, J. Puthussery, S. Gaik, R. Ihly, H. W. Hillhouse, M. Law, Nano Lett. 2010, 10, 1960, https://doi.org/10.1021/nl101284k.

[53] P. R. Brown, D. Kim, R. R. Lunt, N. Zhao, M. G. Bawendi, J. C. Grossman, V. Bulović, ACS Nano 2014, 8, 5863, https://doi.org/10.1021/nn500897c.

[54] K. Lambert, R. K. Čapek, M. I. Bodnarchuk, M. V. Kovalenko, D. Van Thourhout, W. Heiss, Z. Hens, Langmuir 2010, 26, 7732, https://doi. org/10.1021/la904474h.

[55] J. Z. Fan, M. Vafaie, K. Bertens, M. Sytnyk, J. M. Pina, L. Kishore Sagar, O. Ouellette, A. H. Proppe, A. Sedighian Rasouli, Y. Gao, S.-W. Baek, B. Chen, F. Laquai, S. Hoogland, F. Pelayo García de Arquer, W. Heiss, E. H. Sargent, Nano Lett. 2020, 20, 5284, https://doi.org/10.1021/acs.nanolett.0c01614.

[56] C.-H. M. Chuang, P. R. Brown, V. Bulović, M. G. Bawendi, Nat. Mater 2014, 13, 796, https://doi.org/10.1038/nmat3984.

[57] R. Sliz, M. Lejay, J. Z. Fan, M.-J. Choi, S. Kinge, S. Hoogland, T. Fabritius, F. P. García de Arquer, E. H. Sargent, ACS Nano 2019, 13, 11988, https://doi.org/10.1021/acsnano.9b06125.

[58] L. Kim, P. O. Anikeeva, S. A. Coe-Sullivan, J. S. Steckel, M. G. Bawendi, V. Bulović, Nano Lett. 2008, 8, 4513, https://doi.org/10.1021/n18025218.

[59] L. Cademartiri, G. von Freymann, A. C. Arsenault, J. Bertolotti, D. S. Wiersma, V. Kitaev, G. A. Ozin, Small 2005, 1, 1184, https://doi.org/10.1002/smll.200500206.
[60] T. S. Mentzel, D. D. Wanger, N. Ray, B. J. Walker, D. Strasfeld, M. G. Bawendi, M. A. Kastner, Nano Lett. 2012, 12, 4404, https://doi.org/10.1021/nl3022863.

[61] C. Jiang, K. Cao, B. Zhou, Y. Wen, B. Shan, R. Chen, ACS Appl. Electron. Mater. 2020, 2, 155, https://doi.org/10.1021/acsaelm.9b00667.

[62] J. Li, Y. Wang, F. Wan, M. An, M. Li, L. Wang, X. Zhang, Y. Liu, Sol. Energy Mater. Sol. Cells 2020, 209, 110479, https://doi.org/10.1016/j.solmat.2020.110479.

[63] Y. Liu, M. Gibbs, C. L. Perkins, J. Tolentino, M. H. Zarghami, J. Bustamante, M. Law, Nano Lett. 2011, 11, 5349, https://doi.org/10.1021/ nl2028848.

[64] E. Kinder, P. Moroz, G. Diederich, A. Johnson, M. Kirsanova, A. Nemchinov, T. O'Connor, D. Roth, M. Zamkov, J. Am. Chem. Soc. 2011, 133, 20488, https://doi.org/10.1021/ja208670r.

[65] J. Tang, K. W. Kemp, S. Hoogland, K. S. Jeong, H. Liu, L. Levina, M. Furukawa, X. Wang, R. Debnath, D. Cha, K. W. Chou, A. Fischer, A. Amassian, J. B. Asbury, E. H. Sargent, Nat. Mater. 2011, 10, 765, https:// doi.org/10.1038/nmat3118.

[66] A. R. Kirmani, A. D. Sheikh, M. R. Niazi, M. A. Haque, M. Liu, F P. G. de Arquer, J. Xu, B. Sun, O. Voznyy, N. Gasparini, D. Baran, T. Wu, E. H. Sargent, A. Amassian, Adv. Mater. 2018, 30, 1801661, https://doi.org/10.1002/adma.201801661.

[67] M. Liu, F. P. G. de Arquer, Y. Li, X. Lan, G.-H. Kim, O. Voznyy, L. K Jagadamma, A. S. Abbas, S. Hoogland, Z. Lu, J. Y. Kim, A. Amassian, E. H. Sargent, Adv. Mater. 2016, 28, 4142, https://doi.org/10.1002/ adma.201506213.

[68] W. Gao, G. Zhai, C. Zhang, Z. Shao, L. Zheng, Y. Zhang, Y. Yang, X. Li, X. Liu, B. Xu, RSC Adv. 2018, 8, 15149, https://doi.org/10.1039/ C8RA01422A.

[69] P. J. Rodríguez-Cantó, R. Abargues, H. Gordillo, I. Suárez, V. Chirvony, S. Albert, J. Martínez-Pastor, RSC Adv. 2015, 5, 19874 https://doi.org/10.1039/C4RA02812K.

[70] R. W. Crisp, D. M. Kroupa, A. R. Marshall, E. M. Miller, J Zhang, M. C. Beard, J. M. Luther, Sci. Rep. 2015, 5, 9945 , https://doi.org/10.1038/srep09945.

[71] J. M. Luther, M. Law, Q. Song, C. L. Perkins, M. C. Beard, A. J. Nozik, ACS Nano 2008, 2, 271, https://doi.org/10.1021/nn7003348.

[72] M. H. Zarghami, Y. Liu, M. Gibbs, E. Gebremichael, C. Webster, M. Law, ACS Nano 2010, 4, 2475, https://doi.org/10.1021/nn100339b.

[73] F. Hetsch, N. Zhao, S. V. Kershaw, A. L. Rogach, Mater. Today 2013, 16 , 312, https://doi.org/10.1016/j.mattod.2013.08.011.

[74] K. Lu, X. Meng, Z. Liu, J. Chen, Y. Wang, Y. Zhang, X. Zhang, E. Sarnello, G. Shi, R. P. Patil, W. Deng, S. Zhou, M. Gu, Y. Zhong, S. Jeong, X W. Gu, T. Li, X. Ye, W. Ma, Cell Reports Phys. Sci. 2020, 1, 100183 https://doi.org/10.1016/j.xcrp.2020.100183.

[75] M. Biondi, M.-J. Choi, S. Lee, K. Bertens, M. Wei, A. R. Kirmani, G. Lee, H. T. Kung, L. J. Richter, S. Hoogland, Z.-H. Lu, F. P. García de Arquer, E. H. Sargent, ACS Energy Lett. 2021, 468, https://doi.org/10.1021/acsenergylett.0c02500.

[76] M. V Kovalenko, M. Scheele, D. V Talapin, Science 2009, 324, 1417 https://doi.org/10.1126/science.1170524.

[77] M. V. Kovalenko, M. I. Bodnarchuk, J. Zaumseil, J.-S. Lee, D. V. Talapin, J. Am. Chem. Soc. 2010, 132, 10085, https://doi.org/10.1021/ja1024832.

[78] A. Nag, M. V. Kovalenko, J.-S. Lee, W. Liu, B. Spokoyny, D. V. Talapin, J. Am. Chem. Soc. 2011, 133, 10612, https://doi.org/10.1021/ja2029415.

[79] A. H. Ip, S. M. Thon, S. Hoogland, O. Voznyy, D. Zhitomirsky, R. Debnath, L. Levina, L. R. Rollny, G. H. Carey, A. Fischer, K. W. Kemp, I J. Kramer, Z. Ning, A. J. Labelle, K. W. Chou, A. Amassian, E. H. Sargent, Nat. Nanotechnol. 2012, 7, 577, https://doi.org/10.1038/nnano.2012.127.

[80] Q. Lin, H. J. Yun, W. Liu, H.-J. Song, N. S. Makarov, O. Isaienko, T. Nakotte, G. Chen, H. Luo, V. I. Klimov, J. M. Pietryga, J. Am. Chem. Soc. 2017, 139, 6644, https://doi.org/10.1021/jacs.7b01327.

[81] H. Aqoma, M. Al Mubarok, W. T. Hadmojo, E.-H. Lee, T.-W. Kim, T. K. Ahn, S.-H. Oh, S.-Y. Jang, Adv. Mater. 2017, 29, 1605756 , https://doi.org/10.1002/adma.201605756.

[82] L. Hu, Q. Lei, X. Guan, R. Patterson, J. Yuan, C. Lin, J. Kim, X. Geng, A. Younis, X. Wu, X. Liu, T. Wan, D. Chu, T. Wu, S. Huang, Adv. Sci. 2021, 8, 2003138, https://doi.org/10.1002/advs.202003138.

[83] J. Y. Woo, J.-H. Ko, J. H. Song, K. Kim, H. Choi, Y.-H. Kim, D. C. Lee, S. Jeong, J. Am. Chem. Soc. 2014, 136, 8883, https://doi.org/10.1021/ja503957r.

[84] H. Zhang, J. Jang, W. Liu, D. V. Talapin, ACS Nano 2014, 8, 7359, https:// doi.org/10.1021/nn502470v.

[85] X. Lan, O. Voznyy, F. P. García de Arquer, M. Liu, J. Xu, A. H. Proppe, G. Walters, F. Fan, H. Tan, M. Liu, Z. Yang, S. Hoogland, E. H. Sargent, Nano Lett. 2016, 16, 4630, https://doi.org/10.1021/acs.nanolett.6b01957.

[86] M.-J. Choi, F. P. García de Arquer, A. H. Proppe, A. Seifitokaldani, J. Choi, J. Kim, S.-W. Baek, M. Liu, B. Sun, M. Biondi, B. Scheffel, G Walters, D.-H. Nam, J. W. Jo, O. Ouellette, O. Voznyy, S. Hoogland, S. O. Kelley, Y. S. Jung, E. H. Sargent, Nat. Commun. 2020, 11, 103, https://doi.org/10.1038/s41467-019-13437-2. 
[87] B.-J. de Gans, U. S. Schubert, Langmuir 2004, 20, 7789, https://doi.org/10.1021/la049469o.

[88] D. Grosso, J. Mater. Chem. 2011, 21, 17033, https://doi.org/10.1039/c1jm12837j.

[89] N. Zhao, T. P. Osedach, L.-Y. Chang, S. M. Geyer, D. Wanger, M. T. Binda, A. C. Arango, M. G. Bawendi, V. Bulovic, ACS Nano 2010, 4, 3743, https://doi.org/10.1021/nn100129j.

[90] N. Sukharevska, D. Bederak, V. M. Goossens, J. Momand, H. Duim, D. N. Dirin, M. V. Kovalenko, B. J. Kooi, M. A. Loi, ACS Appl. Mater. Interfaces 2021, acsami.0c18204, https://doi.org/10.1021/acsami.0c18204.

[91] I. J. Kramer, G. Moreno-Bautista, J. C. Minor, D. Kopilovic, E. H. Sargent, Appl. Phys. Lett. 2014, 105, 163902, https://doi.org/10.1063/1.4898635.

[92] I. J. Kramer, J. C. Minor, G. Moreno-Bautista, L. Rollny, P. Kanjanaboos, D. Kopilovic, S. M. Thon, G. H. Carey, K. W. W. Chou, D. Zhitomirsky, A. Amassian, E. H. Sargent, Adv. Mater. 2015, 27, 116, https://doi.org/10.1002/adma.201403281.

[93] E. J. D. Klem, D. D. MacNeil, L. Levina, E. H. Sargent, Adv. Mater. 2008, 20,3433, https://doi.org/10.1002/adma.200800326.

[94] M. Singh, H. M. Haverinen, P. Dhagat, G. E. Jabbour, Adv. Mater. 2010, 22 , 673, https://doi.org/10.1002/adma.200901141.

[95] V. Wood, M. J. Panzer, J. Chen, M. S. Bradley, J. E. Halpert, M. G. Bawendi, V. Bulović, Adv. Mater. 2009, 21, 2151 , https://doi.org/10.1002/adma.200803256.

[96] G. Azzellino, F. S. Freyria, M. Nasilowski, M. G. Bawendi, V. Bulović, Adv. Mater. Technol. 2019, 4, 1800727, https://doi.org/10.1002/admt.201800727.

[97] A. YousefiAmin, N. A. Killilea, M. Sytnyk, P. Maisch, K. C. Tam, H.-J. Egelhaaf, S. Langner, T. Stubhan, C. J. Brabec, T. Rejek, M. Halik, K. Poulsen, J. Niehaus, A. Köck, W. Heiss, ACS Nano 2019, 13, acsnano.8b09223, https://doi.org/10.1021/acsnano.8b09223.

[98] Y. Wang, I. Fedin, H. Zhang, D. V Talapin, Science 2017, 357, 385 LP, https://doi.org/10.1126/science.aan2958.

[99] T. Paik, H. Yun, B. Fleury, S.-H. Hong, P. Sung Jo, Y. Wu, S.-J. Oh, M. Cargnello, H. Yang, C. B. Murray, C. R. Kagan, Nano Lett. 2017, 17, 1387, https://doi.org/10.1021/acs.nanolett.6b04279.

[100] C. Ding, F. Liu, Y. Zhang, S. Hayase, T. Masuda, R. Wang, Y. Zhou, Y. Yao, Z. Zou, Q. Shen, ACS Energy Lett. 2020, 5, 3224, https://doi.org/10.1021/acsenergylett.0c01561.

[101] Y. Cao, A. Stavrinadis, T. Lasanta, D. So, G. Konstantatos, Nat. Energy 2016, 1, 16035, https://doi.org/10.1038/nenergy.2016.35

[102] J. Gao, S. Jeong, F. Lin, P. T. Erslev, O. E. Semonin, J. M. Luther, M. C. Beard, Appl. Phys. Lett. 2013, 102, 043506, https://doi.org/10.1063/1.4789434

[103] E. J. D. Klem, H. Shukla, S. Hinds, D. D. MacNeil, L. Levina, E. H. Sargent, Appl. Phys. Lett. 2008, 92, 212105, https://doi.org/10.1063/1.2917800.

[104] C. Kim, S.-W. Baek, J. Kim, B. Kim, C. Lee, J. Y. Park, J.-Y. Lee, ACS Appl. Mater. Interfaces 2020, 12, 57840, https://doi.org/10.1021/acsami.0c14903.

[105] H. Tavakoli Dastjerdi, R. Tavakoli, P. Yadav, D. Prochowicz, M. Saliba, M. M. Tavakoli, ACS Appl. Mater. Interfaces 2019, 11, 26047, https://doi.org/10.1021/acsami.9b08466.

[106] O. Voznyy, D. Zhitomirsky, P. Stadler, Z. Ning, S. Hoogland, E. H. Sargent, ACS Nano 2012, 6, 8448, https://doi.org/10.1021/nn303364d.

[107] S. J. Oh, N. E. Berry, J.-H. Choi, E. A. Gaulding, T. Paik, S.H. Hong, C. B. Murray, C. R. Kagan, ACS Nano 2013, 7, 2413, https://doi.org/10.1021/nn3057356.

[108] M. M. Ackerman, X. Tang, P. Guyot-Sionnest, ACS Nano 2018, 12, 7264, https://doi.org/10.1021/acsnano.8b03425.

[109] W. Koh, A. Y. Koposov, J. T. Stewart, B. N. Pal, I. Robel, J. M. Pietryga, V. I. Klimov, Sci. Rep. 2013, 3, 2004, https://doi.org/10.1038/srep02004

[110] P. Moroz, G. Liyanage, N. N. Kholmicheva, S. Yakunin, U. Rijal, P. Uprety, E. Bastola, B. Mellott, K. Subedi, L. Sun, M. V. Kovalenko, M. Zamkov, Chem. Mater. 2014, 26, 4256, https://doi.org/10.1021/cm501739h.

[111] M. Al Mubarok, F. T. A. Wibowo, H. Aqoma, N. Vamsi Krishna, W. Lee, D. Y. Ryu, S. Cho, I. H. Jung, S.-Y. Jang, ACS Energy Lett. 2020, 5, 3452, https://doi.org/10.1021/acsenergylett.0c01838.

[112] Y. Xue, F. Yang, J. Yuan, Y. Zhang, M. Gu, Y. Xu, X. Ling, Y. Wang, F. Li, T. Zhai, J. Li, C. Cui, Y. Chen, W. Ma, ACS Energy Lett. 2019, 4, 2850, https://doi.org/10.1021/acsenergylett.9b02301.

[113] Y. Zhang, M. Gu, N. Li, Y. Xu, X. Ling, Y. Wang, S. Zhou, F. Li, F. Yang, K. Ji, J. Yuan, W. Ma, J. Mater. Chem. A 2018, 6, 24693, https://doi.org/10.1039/C8TA09164A.

[114] A. Kiani, B. R. Sutherland, Y. Kim, O. Ouellette, L. Levina, G. Walters, C.T. Dinh, M. Liu, O. Voznyy, X. Lan, A. J. Labelle, A. H. Ip, A. Proppe, G. H. Ahmed, O. F. Mohammed, S. Hoogland, E. H. Sargent, Appl. Phys. Lett. 2016, 109, 183105, https://doi.org/10.1063/1.4966217.

[115] J. E. Lewis, S. Wu, X. J. Jiang, Nanotechnology 2010, 21, 455402, https://doi.org/10.1088/0957-4484/21/45/455402.

[116] C. Ding, Y. Zhang, F. Liu, Y. Kitabatake, S. Hayase, T. Toyoda, R. Wang, K. Yoshino, T. Minemoto, Q. Shen, Nanoscale Horizons 2018, 3, 417, https://doi.org/10.1039/C8NH00030A

[117] M. Ono, T. Nishihara, T. Ihara, M. Kikuchi, A. Tanaka, M. Suzuki, Y. Kanemitsu, Chem. Sci. 2014, 5, 2696, https://doi.org/10.1039/c4sc00436a.
118] T. Nishihara, H. Tahara, M. Okano, M. Ono, Y. Kanemitsu, J. Phys. Chem. Lett. 2015, 6, 1327, https://doi.org/10.1021/acs.jpclett.5b00293.

[119] T. Zhao, E. D. Goodwin, J. Guo, H. Wang, B. T. Diroll, C. B. Murray, C. R. Kagan, ACS Nano 2016, 10, 9267, https://doi.org/10.1021/acsnano.6b03175.

[120] Z. Ning, H. Dong, Q. Zhang, O. Voznyy, E. H. Sargent, ACS Nano 2014 8, 10321, https://doi.org/10.1021/nn503569p

[121] K. Szendrei, W. Gomulya, M. Yarema, W. Heiss, M. A. Loi, Appl. Phys. Lett. 2010, 97, 203501, https://doi.org/10.1063/1.3518067.

[122] J. Z. Fan, M. Liu, O. Voznyy, B. Sun, L. Levina, R. Quintero-Bermudez, M. Liu, O. Ouellette, F. P. Garcia de Arquer, S. Hoogland, E. H Sargent, ACS Appl. Mater. Interfaces 2017, acsami.7b11449, https://doi. org/10.1021/acsami.7b11449.

[123] D. K. Smith, J. M. Luther, O. E. Semonin, A. J. Nozik, M. C. Beard, ACS Nano 2011, 5, 183, https://doi.org/10.1021/nn102878u.

[124] D. M. Balazs, N. Rizkia, H.-H. Fang, D. N. Dirin, J. Momand, B. J. Kooi, M. V. Kovalenko, M. A. Loi, ACS Appl. Mater. Interfaces 2018, 10, 5626, https://doi.org/10.1021/acsami.7b16882.

[125] J. J. Choi, C. R. Bealing, K. Bian, K. J. Hughes, W. Zhang, D. M Smilgies, R. G. Hennig, J. R. Engstrom, T. Hanrath, J. Am. Chem. Soc. 2011, 133, 3131, https://doi.org/10.1021/ja110454b.

[126] T. Hanrath, J. J. Choi, D. M. Smilgies, ACS Nano 2009, 3, 2975, https://doi.org/10.1021/nn901008r.

[127] J. Jean, T. S. Mahony, D. Bozyigit, M. Sponseller, J. Holovský, M. G. Bawendi, V. Bulović, ACS Energy Lett. 2017, 2, 2616 , https://doi.org/10.1021/acsenergylett.7b00923.

[128] R. Bose, J. F. McMillan, J. Gao, K. M. Rickey, C. J. Chen, D. V. Talapin, C. B. Murray, C. W. Wong, Nano Lett. 2008, 8, 2006, https://doi.org/10.1021/n18011243.

[129] A. A. Bakulin, S. Neutzner, H. J. Bakker, L. Ottaviani, D. Barakel, Z Chen, ACS Nano 2013, 7, 8771, https://doi.org/10.1021/nn403190s.

[130] S. W. Clark, J. M. Harbold, F. W. Wise, J. Phys. Chem. C 2007, 111, 7302, https://doi.org/10.1021/jp0713561

[131] J. S. Wang, B. Ullrich, A. Das, C. M. Wai, G. J. Brown, C. K. Dass, J. R. Hendrickson, RSC Adv. 2016, 6, 48651, https://doi.org/10.1039/C6RA03632E.

[132] S. Yakunin, D. N. Dirin, L. Protesescu, M. Sytnyk, S. Tollabimazraehno, M. Humer, F. Hackl, T. Fromherz, M. I. Bodnarchuk, M. V. Kovalenko, W. Heiss, ACS Nano 2014, 8, 12883, https://doi.org/10.1021/nn5067478.

[133] Y. Wang, K. Lu, L. Han, Z. Liu, G. Shi, H. Fang, S. Chen, T. Wu, F. Yang, M. Gu, S. Zhou, X. Ling, X. Tang, J. Zheng, M. A. Loi, W. Ma, Adv. Mater. 2018, 30, 1704871, https://doi.org/10.1002/adma.201704871.

[134] H. C. Leventis, F. O’Mahony, J. Akhtar, M. Afzaal, P. O’Brien, S. A Haque, J. Am. Chem. Soc. 2010, 132, 2743, https://doi.org/10.1021/ ja909172p.

[135] D. Bozyigit, V. Wood, J. Mater. Chem. C 2014, 2, 3172, https://doi.org/10.1039/C3TC32235A.

[136] W. M. M. Lin, N. Yazdani, O. Yarema, S. Volk, M. Yarema, T. Kirchartz, V. Wood, J. Chem. Phys. 2019, 151, 241104 https://doi.org/10.1063/1.5129159.

[137] S. Kahmann, M. A. Loi, Appl. Phys. Rev. 2020, 7, 041305, https://doi.org/10.1063/5.0019800.

[138] S. Volk, N. Yazdani, V. Wood, J. Phys. Chem. Lett. 2020, 11, 9255 https://doi.org/10.1021/acs.jpclett.0c01417.

[139] S. Volk, N. Yazdani, O. Yarema, M. Yarema, V. Wood, ACS Appl. Electron. Mater. 2020, 2, 398, https://doi.org/10.1021/acsaelm.9b00685.

[140] R. H. Gilmore, Y. Liu, W. Shcherbakov-Wu, N. S. Dahod, E. M. Y. Lee, M. C. Weidman, H. Li, J. Jean, V. Bulovic, A. P. Willard, J. C. Grossman, W. A. Tisdale, Matter 2019, 1, 250, https://doi.org/10.1016/j. matt.2019.05.015.

[141] D. M. Balazs, M. A. Loi, Adv. Mater. 2018, 30, 1800082 , https://doi.org/10.1002/adma.201800082

[142] W. Zhou, Y. Shang, F. P. García de Arquer, K. Xu, R. Wang, S. Luo, X. Xiao, X. Zhou, R. Huang, E. H. Sargent, Z. Ning, Nat. Electron. 2020, 3, 251, https://doi.org/10.1038/s41928-020-0388-X.

[143] D. A. Onishchuk, A. S. Pavlyuk, P. S. Parfenov, A. P. Litvin, I. R Nabiev, Opt. Spectrosc. 2018, 125, 751, https://doi.org/10.1134/ S0030400X1811022X.

[144] I. Ramiro, O. Özdemir, S. Christodoulou, S. Gupta, M Dalmases, I. Torre, G. Konstantatos, Nano Lett. 2020, 20, 1003 https://doi.org/10.1021/acs.nanolett.9b04130

[145] G. V. Shcherbatyuk, R. H. Inman, C. Wang, R. Winston, S. Ghosh, Appl. Phys. Lett. 2010, 96, 191901, https://doi.org/10.1063/1.3422485.

[146] M. I. Nugraha, H. Kim, B. Sun, M. A. Haque, F. P. G. Arquer, D. R. Villalva, A. El Labban, E. H. Sargent, H. N. Alshareef, D. Baran, Adv. Energy Mater. 2019, 9, 1803049, https://doi.org/10.1002/ aenm. 201803049

[147] S. Kim, J. Kim, Y. H. Lee, Adv. Mater. 2020, 32, 1908461 https://doi.org/10.1002/adma.201908461.

[148] J. M. Luther, J. Gao, M. T. Lloyd, O. E. Semonin, M. C. Beard, A. J. Nozik Adv. Mater. 2010, 22, 3704, https://doi.org/10.1002/adma.201001148. 
[149] J. Gao, C. L. Perkins, J. M. Luther, M. C. Hanna, H.-Y. Chen, O. E. Semonin, A. J. Nozik, R. J. Ellingson, M. C. Beard, Nano Lett. 2011, 11, 3263, https://doi.org/10.1021/nl2015729.

[150] A. J. Labelle, S. M. Thon, S. Masala, M. M. Adachi, H. Dong, M. Farahani, A. H. Ip, A. Fratalocchi, E. H. Sargent, Nano Lett. 2015, 15, 1101, https://doi.org/10.1021/nl504086v.

[151] X. Lan, O. Voznyy, A. Kiani, F. P. García de Arquer, A. S. Abbas, G.-H. Kim, M. Liu, Z. Yang, G. Walters, J. Xu, M. Yuan, Z. Ning, F. Fan, P. Kanjanaboos, I. Kramer, D. Zhitomirsky, P. Lee, A. Perelgut, S. Hoogland, E. H. Sargent, Adv. Mater. 2016, 28, 299, https://doi.org/10.1002/adma.201503657.

[152] J. Xu, O. Voznyy, M. Liu, A. R. Kirmani, G. Walters, R. Munir, M. Abdelsamie, A. H. Proppe, A. Sarkar, F. P. García de Arquer, M. Wei, B. Sun, M. Liu, O. Ouellette, R. Quintero-Bermudez, J. Li, J. Fan, L. Quan, P. Todorovic, H. Tan, S. Hoogland, S. O. Kelley, M. Stefik, A. Amassian, E. H. Sargent, Nat. Nanotechnol. 2018, 13, 456, https://doi.org/10.1038/s41565-018-0117-z.

[153] G. J. Supran, K. W. Song, G. W. Hwang, R. E. Correa, J. Scherer, E. A Dauler, Y. Shirasaki, M. G. Bawendi, V. Bulovic, Adv. Mater. 2015, 27, 1437, https://doi.org/10.1002/adma.201404636.

[154] J. M. Pietryga, D. J. Werder, D. J. Williams, J. L. Casson, R. D. Schaller, V. I. Klimov, J. A. Hollingsworth, J. Am. Chem. Soc. 2008, 130, 4879, https://doi.org/10.1021/ja710437r.

[155] X. Zhang, Y. Chen, L. Lian, Z. Zhang, Y. Liu, L. Song, C. Geng, J. Zhang, S. Xu, Nano Res. 2021, 14, 628, https://doi.org/10.1007/s12274-020-3081-5.

[156] N. Yazdani, S. Volk, O. Yarema, M. Yarema, V. Wood, ACS Photonics 2020 7, 1088, https://doi.org/10.1021/acsphotonics.0c00034.

[157] Y. Zhu, J.-X. Cheng, J. Chem. Phys. 2020, 152, 020901, https://doi.org/10.1063/1.5129123.

[158] M. C. Weidman, D.-M. Smilgies, W. A. Tisdale, Nat. Mater. 2016, 15, 775, https://doi.org/10.1038/nmat4600.

[159] E. Serpetzoglou, I. Konidakis, G. Kakavelakis, T. Maksudov, E. Kymakis, E. Stratakis, ACS Appl. Mater. Interfaces 2017, 9, 43910, https://doi.org/10.1021/acsami.7b15195.

[160] J. J. van Franeker, K. H. Hendriks, B. J. Bruijnaers, M. W. G. M. Verhoeven, M. M. Wienk, R. A. J. Janssen, Adv. Energy Mater. 2017, 7, 1601822 , https://doi.org/10.1002/aenm.201601822.
[161] C. Gréboval, P. Rastogi, J. Qu, A. Chu, J. Ramade, A. Khalili, C. Dabard, T. H. Dang, H. Cruguel, A. Ouerghi, N. Witkowski, M. G. Silly, E. Lhuillier, J. Phys. Chem. C 2020, 124, 23400, https://doi.org/10.1021/acs.jpcc.0c06751.

[162] Q. Li, X. Hu, Y. Bai, M. Alattar, D. Ma, Y. Cao, Y. Hao, L. Wang, C. Jiang, Food Chem. Toxicol. 2013, 60, 213, https://doi.org/10.1016/j.fct.2013.07.046.

[163] L. Truong, I. S. Moody, D. P. Stankus, J. A. Nason, M. C. Lonergan, R. L. Tanguay, Arch. Toxicol. 2011, 85, 787 , https://doi.org/10.1007/s00204-010-0627-4.

[164] J. Ramade, J. Qu, A. Chu, C. Gréboval, C. Livache, N. Goubet, B. Martinez, G. Vincent, E. Lhuillier, ACS Photonics 2020, 7, 272 https://doi.org/10.1021/acsphotonics.9b01542.

[165] Q. Xu, L. Meng, K. Sinha, F. I. Chowdhury, J. Hu, X. Wang, ACS Photonics 2020, 7, 1297, https://doi.org/10.1021/acsphotonics.0c00363.

[166] M. Bernechea, N. C. Miller, G. Xercavins, D. So, A Stavrinadis, G. Konstantatos, Nat. Photonics 2016, 10, 521, https://doi.org/10.1038/nphoton.2016.108.

[167] E. H. Robinson, M. J. Turo, J. E. Macdonald, Chem. Mater. 2017, 29, 3854, https://doi.org/10.1021/acs.chemmater.6b05080.

[168] C. Yan, E. Gu, F. Liu, Y. Lai, J. Li, Y. Liu, Nanoscale 2013, 5, 1789, https://doi.org/10.1039/c3nr33268c.

\section{License and Terms}

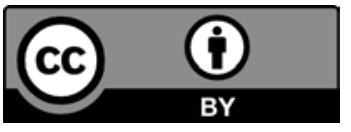

This is an Open Access article under the terms of the Creative Commons Attribution License CC BY 4.0. The material may not be used for commercial purposes.

The license is subject to the CHIMIA terms and conditions: (http:// chimia.ch/component/sppagebuilder/?view $=$ page $\& i d=12$ ).

The definitive version of this article is the electronic one that can be found at https://doi.org/10.2533/chimia.2021.398 